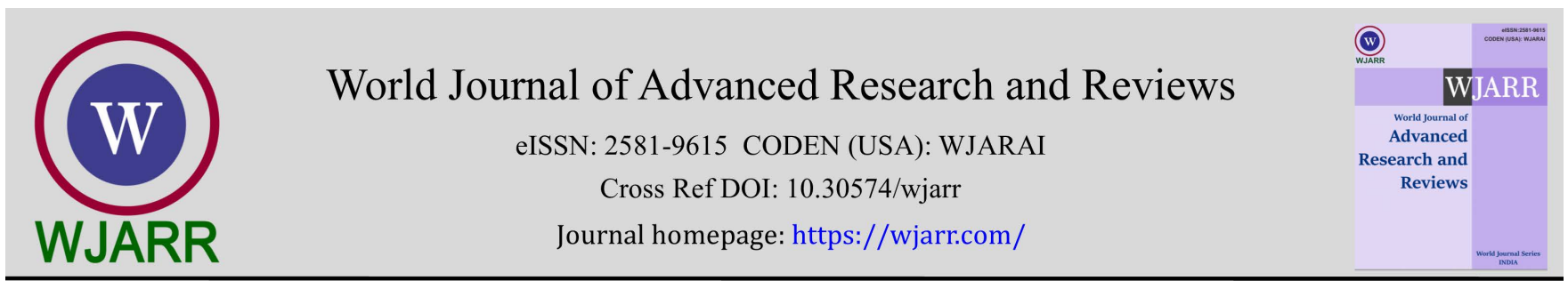

(RESEARCH ARTicle)

Check for updates

\title{
A study of deformation around the Korea strait prior to MW9.0 Tohoku earthquake
}

\author{
Michael Timothy Tasliman ${ }^{1,2,{ }^{*}}$ and Hongsik Yun ${ }^{1}$ \\ ${ }_{1}^{1}$ School of Civil, Architectural and Environmental System Engineering, Sungkyunkwan University, Suwon, South Korea. \\ 2 Ministry of Agrarian Affairs and Spatial Planning/National Land Agency, Jakarta, Indonesia.
}

World Journal of Advanced Research and Reviews, 2021, 12(02), 120-142

Publication history: Received on 24 September 2021; revised on 31 October 2021; accepted on 02 November 2021

Article DOI: https://doi.org/10.30574/wjarr.2021.12.2.0554

\begin{abstract}
On 11 March 2011, a great earthquake with magnitude 9.0 has occurred in Tohoku, Japan, more than 1,000 km from South Korea. In fact, seismicity rate in South Korea has increased since the 2011 Tohoku earthquake, although detailed evaluation of its effects on the Korean Peninsula remains incomplete. Now, the high precision space geodesy techniques play a key role in monitoring the crustal strain state and energy variation. This study attempts to evaluate crustal deformation around the Korean Strait after 2011 Tohoku earthquake through a detailed analysis recorded by GPS. Moreover, this study found a different fault characteristic in Japan affect the station displacement prior to GPS data observed among 2011 to 2012. After a year, the strain in Japan found in direction WNW-ESE, while in Korea found in direction WSW-ENE. This finding suggests the likelihood of the existence of a certain tectonic line between the southern part of Korea peninsula and Japan.
\end{abstract}

Keywords: Displacement; Global Positioning System; Strain; Time series; Tohoku earthquake; Velocity

\section{Introduction}

The 2011 Mw9.0 Tohoku earthquake, Japan, is one of the largest earthquakes ever observed, causing an abrupt change in regional seismicity and large-scale crustal deformation [1,2]. Given the mandate of improving our understanding of the associated seismic hazard and utilizing the well-instrumented deformation signatures of this earthquake for our understanding of crustal mechanics, it is important to understand the coseismic slip, and how it may be influenced by the heterogeneity of the elastic structure that surrounds the plate interface.

The coseismic slip of the Tohoku earthquake has been estimated from various observations including teleseismic waveforms [3], strong motion [4], and tsunami propagation [5], as well as from geodesy. The Japanese islands are covered with one of the world's most dense GPS networks and seafloor geodetic stations that recorded coseismic surface displacements caused by the earthquake. On the other hand, the seismicity rate in South Korea has increased since the 2011 Tohoku earthquake and [6] suggested that this enhanced activity is a direct consequence of the 2011 event, although detailed evaluation of its effects on the Korean Peninsula remains incomplete. There was a significant coseismic surface displacement not only in the Japanese Islands [2] but throughout East Asia (up to 3,000 km from the epicenter) [7,8,9]. Coseismic and postseismic crustal deformation of South Korea due to the Tohoku earthquake as estimated from Global Positioning System (GPS) data, was dominated by dilatation; that is, either the absolute magnitude of the positive maximum principal straining axis was greater than that of the negative minimum principal straining axis or both the maximum and minimum principal straining axes were positive [10,11]. Focal mechanism solutions of earthquakes in South Korea indicate that the dominant type of earthquake faulting was strike slip, while thrust and normal faulting are relatively uncommon $[12,13]$.

\footnotetext{
${ }^{*}$ Corresponding author: Michael Timothy Tasliman

School of Civil, Architectural and Environmental System Engineering, Sungkyunkwan University, Suwon, South Korea. 
Current seismotectonic province models of the Korean Peninsula have been based on lithology, tectonic history, and historical and instrumental seismic records and do not incorporate estimates of crustal deformation from geodetic data. In this study, we evaluate crustal deformation on the Korean Peninsula after 2011 Tohoku earthquake through a detailed analysis of velocity fields recorded by GPS. Now the high precision space geodesy techniques play a key role in monitoring the crustal strain state and energy variation. Meanwhile, the significant strain accumulated caused by the tectonic activities (such as earthquakes) will provide an essential variation of the strain and comprehensive understanding of strain accumulation pattern are beneficial to reveal the physical process of crustal tectonic activities and to evaluate the earthquake risk. In addition, the GPS stations located near to our study area are used to estimate the strain rates, in attempt to estimate the boundary of Eurasian plate.

\section{Operation Principle of Global Positioning System}

GPS is a satellite-based radio positioning system developed by the U.S. Department of Defense (DOD) for accurate positioning and navigation. Radio signals are used from a constellation of earth-orbiting satellites to determine the 3D position of a receiver. The system consists of 21 satellites and three spare satellites orbiting approximately 20,000 km above the earth's surface in six orbital planes, having a period of 12 hours. GPS is an all-weather positioning system providing 24-hour world-wide coverage with at least four satellites in view at any time [14,15]. The system has been fully operational since 1993 .

GPS has three main components: the satellite system, the control system, and the users. The control system is operated by the U.S. Air Force for the Joint Program Office (JPO) of the DOD. The system consists of five monitoring stations distributed around the world. The role of these stations is to monitor the health of the satellites. These tracking stations receive signals from the satellites and transmit the collected data to the master station where new ephemerides are computed, and the navigation messages are prepared for uploading to the satellites.

\subsection{User Segment}

Users are the third component of GPS. Civilian users wish to determine their positions using GPS signals. There are mainly three observables which have been implemented in most GPS receivers:

- Pseudorange

- Carrier beat phase

- The rate of phase change

Both position and velocity of a moving platform can be calculated by measuring signals from different GPS satellites [15].

\subsection{GPS Signals}

The GPS signals are transmitted autonomously from all GPS satellites on two carrier frequencies: L1 frequency at 1575.42 MHz and L2 frequency at $1227.60 \mathrm{MHz}$. C/A code of $1.023 \mathrm{MHz}$ is modulated on the L1 carrier and P code of $10.23 \mathrm{MHz}$ is modulated on both L1 and L2 carriers. A satellite message containing the satellites' ephemeris is also modulated on both carriers. A summary of the signal components is given in Table 1.

Table 1 GPS signal components [6]

\begin{tabular}{|c|c|c|c|c|c|}
\hline Carrier & Frequency & Wavelength & Modulation & Frequency & Chip length \\
\hline L1 & $1575.42 \mathrm{MHz}$ & $19 \mathrm{~cm}$ & $\begin{array}{l}\text { C/A code } \\
\text { P code } \\
\text { Message }\end{array}$ & $\begin{array}{l}1.023 \mathrm{MHz} \\
10.23 \mathrm{MHz} \\
50 \mathrm{MHz}\end{array}$ & $\begin{array}{l}293 \mathrm{~m} \\
29.3 \mathrm{~m}\end{array}$ \\
\hline $\mathrm{L} 2$ & $1227.60 \mathrm{MHz}$ & $24 \mathrm{~cm}$ & $\begin{array}{l}\text { P code } \\
\text { Message }\end{array}$ & $\begin{array}{l}10.23 \mathrm{MHz} \\
50 \mathrm{MHz}\end{array}$ & $29.3 \mathrm{~m}$ \\
\hline
\end{tabular}

There are two types of receivers; Single Frequency (receiving only L1 signal) and Dual Frequency (receiving both L1 and L2 signals). Most C/A code receivers correlate the incoming signal from a satellite with a replica of the code generated in the receiver. The dual frequency receivers provide access to $\mathrm{P}$ code data through code correlation resulting 
in a full L2 wavelength of $24 \mathrm{~cm}$. Due to a high absolute accuracy available using P codes, Selective Availability (SA) is turned on to deteriorate the positioning accuracy.

The type of data that a receiver collects has a direct impact on both achievable accuracy and its price. The C/A code receivers are the least expensive receivers on the market which determine real time positions with horizontal accuracy of $100 \mathrm{~m}$ and vertical accuracy of $156 \mathrm{~m}$ [17]. P code receivers provide accuracies at the level of $25 \mathrm{~m}$ (horizontal) and $30 \mathrm{~m}$ (vertical) in real time mode. Access to P code is limited to U.S. and NATO military users.

Receivers which compute their positions based on carrier phase observations are more accurate because of the much finer resolution of the $19 \mathrm{~cm}$ and $24 \mathrm{~cm}$ carrier wavelengths. The most sophisticated and expensive receivers are dual frequency $P$ code receivers that provide accuracy ranging from a part per million to a few part per billion. Between these two extreme cases, one can find a wide range of receivers which meet the users' accuracy requirements.

\subsection{GPS Observables}

A pseudorange (code observation) is the difference between the transmission time at the satellite and the reception time at the receiver [18]. Pseudorange between the satellite and the receiver is obtained by scaling it using the speed of light. The observation equation for a pseudorange is given as [15];

$$
p=\rho+c(d t-d T)+d_{\rho}+d_{\text {ion }}+d_{\text {trop }}+\varepsilon_{p}
$$

where

$\mathrm{p}$ is the observed pseuodorange,

$\rho$ is the unknown satellite-receiver range,

c is the speed of light,

$\mathrm{dt}$ is the satellite clock error,

$\mathrm{dT}$ is the receiver clock error,

$\mathrm{d} \rho$ is the orbital error,

$\mathrm{d}_{\text {ion }}$ is the ionospheric error,

$\mathrm{d}_{\text {trop }}$ is the tropospheric error,

$\varepsilon \rho$ is the code measurement noise and multipath.

The code measurement noise, $\varepsilon \rho$, is a function of the code receiver noise, $\varepsilon$ prx , and multipath, $\varepsilon$ mult [17]. The satellitereceiver range, $\rho$, has the form of:

$$
\rho=\sqrt{\left(X^{s}-X_{r}\right)+\left(Y^{s}-Y_{r}\right)+\left(Z^{s}-Z_{r}\right)}
$$

where

$\left(\mathrm{X}^{\mathrm{S}}, \mathrm{Y}^{\mathrm{S}}, \mathrm{Z}^{\mathrm{S}}\right)$ are satellite coordinates computed using broadcast ephemeris,

$\left(\mathrm{X}_{\mathrm{r}}, \mathrm{Y}_{\mathrm{r}}, \mathrm{Z}_{\mathrm{r}}\right)$ are the unknown receiver coordinates.

For single point positioning, the number of unknowns are four $\left(\mathrm{X}_{\mathrm{r}}, \mathrm{Y}_{\mathrm{r}}, \mathrm{Z}_{\mathrm{r}}, \mathrm{dT}\right)$, therefore, a minimum of four satellites are required to solve for a solution at a single epoch.

The carrier phase observation is a measure of the misalignment between an incoming signal and replica of it generated by the receiver oscillator when a satellite is locked on. If a continuous lock is assumed, this measurement is a sum of the initial phase misalignment at epoch $t_{0}$ and the number of integer cycles from epoch $t_{0}$ to the current epoch $t$. The measured carrier phase can be written as [18]: 


$$
\phi_{\text {measured }}=\text { fraction }(\phi)+\operatorname{integer}\left(\phi, \mathrm{t}_{0}, \mathrm{t}\right)
$$

Carrier phase measurements are converted from cycles to units of lengths by their wavelengths. An ambiguity term (the unknown number of integer cycles between the satellite and receiver at starting epoch $t_{0}$ ) should be added to carrier phase measurement in order to represent a satellite-receiver range. The carrier phase observation equation is written as [17]:

where

$$
\phi=\rho+\mathrm{c}(\mathrm{dt}-\mathrm{dT})+\lambda \mathrm{N}+\mathrm{d}_{\rho}-\mathrm{d}_{\text {ion }}+\mathrm{d}_{\text {trop }}+\varepsilon_{\phi}
$$

$\phi$ is the observed carrier phase,

$\rho$ is the unknown satellite-receiver range,

$\mathrm{c}$ is the speed of light,

$\mathrm{dt}$ is the satellite clock error,

$\mathrm{dT}$ is the receiver clock error,

$\lambda$ is the carrier wavelength,

$\mathrm{N}$ is the unknown integer cycle ambiguity,

$\mathrm{d} \rho$ is the orbital error,

dion is the ionospheric error,

$\mathrm{d}_{\text {trop }}$ is the tropospheric error,

$\varepsilon_{\phi}$ is the carrier phase measurement noise and multipath.

The differences between pseudorange and carrier phase observation equations are the addition of ambiguity term, $\lambda \mathrm{N}$, for carrier phase observations and the reversal of signs for the ionospheric correction term $d_{\text {ion }}$ due to the phase advance, while code is delayed.

Doppler frequency is the third fundamental GPS observation which is the first derivative of the carrier phase with respect to time. The Doppler frequency is measured on the pseudorange. The observation equation for GPS Doppler frequency can be written as [19]:

$$
\phi=\rho+c(d t-d T)+d_{\rho}-d_{\text {ion }}+d_{\text {trop }}+\varepsilon_{\phi}
$$

where $(\cdot)$ denotes a time derivative. As seen in the above equation, this measurement is not a function of the carrier phase ambiguity, therefore, it is free from cycle slips and can be used to determine the receiver velocity.

\subsection{Differential GPS}

In order to achieve high accuracy for geodetic positioning, differential GPS techniques are used to eliminate or reduce several GPS error sources.

\subsubsection{Single Differencing}

The observation equations for pseudorange, carrier phase, and Doppler frequency contain bias terms such as satellite and receiver clock errors, orbital errors, and atmospheric effects. Many of these errors are spatially correlated to some extent between the receivers tracking simultaneous satellites. Some errors are satellite dependent (orbital, atmospheric, and satellite clock errors) and some errors are receiver dependent (receiver clock error). Single 
differencing (between satellites or between receivers) and double differencing (between receivers and between satellites) of GPS observations can be applied to eliminate or effectively reduce the common errors. The single "between receivers" and "between satellites" differences are shown in Figures 1 and Figure 2.

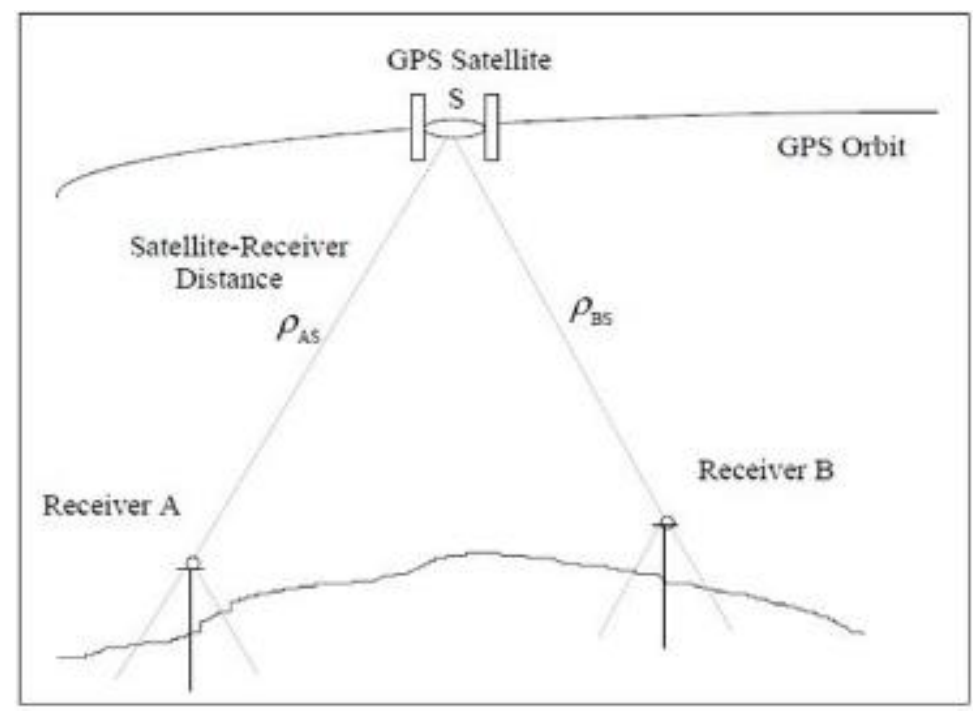

Figure 1 Single differencing between receivers

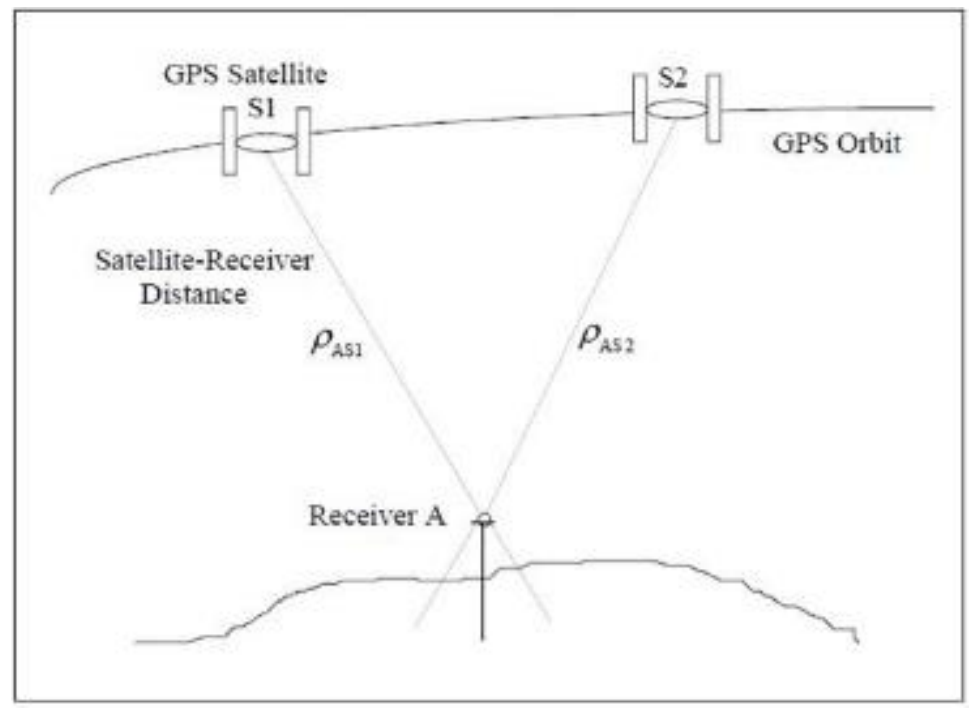

Figure 2 Single differencing between satellites

The single difference equations for the pseudorange, carrier phase, and Doppler frequency are [17]:

"between receivers"

"between satellites"

$$
\begin{gathered}
\Delta \rho=\Delta \rho+\Delta \mathrm{d}_{\rho}-\mathrm{c} \Delta \mathrm{dT}+\Delta \mathrm{d}_{\text {ion }}+\Delta \mathrm{d}_{\text {trop }}+\Delta \varepsilon_{\mathrm{p}} \\
\Delta \phi=\Delta \rho+\Delta \mathrm{d}_{\rho}-\mathrm{c} \Delta \mathrm{dT}+\lambda \Delta \mathrm{N}-\Delta \mathrm{d}_{\text {ion }}+\Delta \mathrm{d}_{\text {trop }}+\Delta \varepsilon_{\phi} \\
\Delta \phi=\Delta \rho+\Delta \mathrm{d}_{\rho}-\mathrm{c} \Delta \mathrm{dT}-\Delta \mathrm{d}_{\text {ion }}+\Delta \mathrm{d}_{\text {trop }}+\Delta \varepsilon_{\phi}
\end{gathered}
$$

$$
\begin{gathered}
\nabla \rho=\nabla \rho+\nabla \mathrm{d}_{\rho}-c \nabla \mathrm{dt}+\nabla \mathrm{d}_{\text {ion }}+\nabla \mathrm{d}_{\text {trop }}+\nabla \varepsilon_{\mathrm{p}} \\
\nabla \phi=\nabla \rho+\nabla \mathrm{d}_{\rho}-\mathrm{c} \nabla \mathrm{dt}+\lambda \nabla \mathrm{N}-\nabla \mathrm{d}_{\text {ion }}+\nabla \mathrm{d}_{\text {trop }}+\nabla \varepsilon_{\phi}
\end{gathered}
$$




$$
\nabla \phi=\nabla \rho+\nabla \mathrm{d}_{\rho}-\mathrm{c} \nabla \mathrm{dT}-\nabla \mathrm{d}_{\text {ion }}+\nabla \mathrm{d}_{\text {trop }}+\nabla \varepsilon_{\phi}
$$

where

$\Delta$ denotes a single difference operator between receivers,

$\nabla$ denotes a single difference operator between satellites.

In the single difference observable (between receivers), the satellite clock error has been eliminated and the orbital error and atmospheric effects have been reduced and their residuals can be neglected for monitor-remote distances less than $30 \mathrm{~km}$ under normal atmospheric conditions. The relative receiver clock error, however, may be significant and must be estimated along with the parameters of position, velocity, and carrier phase ambiguity [19]. Single difference observable (between satellites) eliminates receiver clock error.

\subsubsection{Double Differencing}

This technique is based on taking difference between receivers and between satellites (Figure 3).

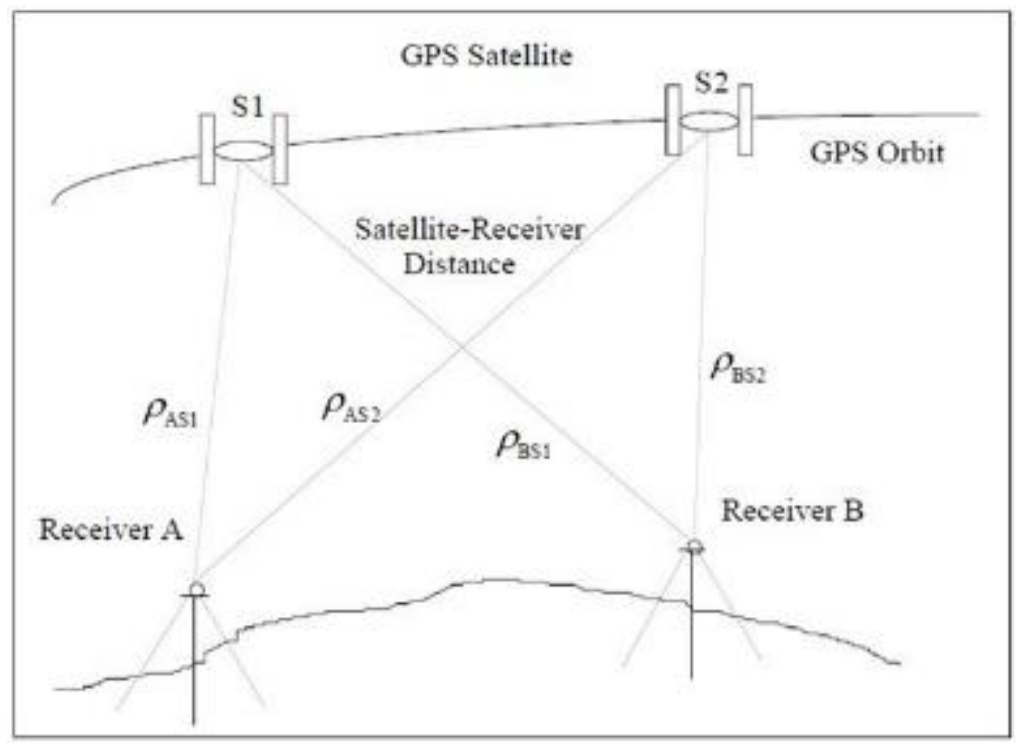

Figure 3 Double differencing

Double difference observation equations are written as [19]:

$$
\begin{gathered}
\nabla \Delta \rho=\nabla \Delta \rho+\nabla \Delta \mathrm{d}_{\rho}+\nabla \Delta \mathrm{d}_{\text {ion }}+\nabla \Delta \mathrm{d}_{\text {trop }}+\nabla \Delta \varepsilon_{\mathrm{p}} \\
\nabla \Delta \phi=\nabla \Delta \rho+\nabla \Delta \mathrm{d}_{\rho}+\lambda \nabla \Delta \mathrm{N}-\nabla \Delta \mathrm{d}_{\text {ion }}+\nabla \Delta \mathrm{d}_{\text {trop }}+\nabla \Delta \varepsilon_{\phi} \\
\nabla \Delta \phi=\nabla \Delta \rho+\nabla \Delta \mathrm{d}_{\rho}-\nabla \Delta \mathrm{d}_{\text {ion }}+\nabla \Delta \mathrm{d}_{\text {trop }}+\nabla \Delta \varepsilon_{\phi}
\end{gathered}
$$

where $\nabla \Delta$ denotes the double difference operator between two stations and two satellites.

The advantage of using this observable is that both the receiver and satellite clock errors have been canceled out, while the disadvantage is increased noise. This method also allows to optimally exploit the integer nature of carrier phase ambiguity. Double differencing GPS positioning is considered as the best processing method [20,21,22]. This observable still contains the double difference ambiguity term which has to be resolved before the beginning of the kinematic mission and then fixed in kinematic surveys. In airborne kinematic positioning, cycle slips may often occur in carrier phase observation due to aircraft dynamics (e.g. turning) and multipath effects. Therefore, it is mandatory to resolve ambiguity on the fly for precise GPS positioning. 


\subsection{Algorithm for Kinematic GPS}

There are mainly two algorithms being used in kinematic GPS: Kalman filtering and least squares $[20,21,23,24]$. Under certain conditions, one algorithm is equivalent to the other one in terms of computational aspects. It is important to know about the features of the algorithms and their relationships in kinematic GPS.

\subsubsection{Kalman Filter Algorithm}

Kalman filter is an optimal estimator, i.e. infers parameters of interest from indirect, inaccurate and uncertain observations. The filter uses a Gaussian approximation and minimizes the mean square error of the estimated parameters and only propagates the mean and covariance of the predictive and posterior distributions. The purpose of filtering is to extract the required information from a signal ignoring everything else. The general state-space model is given as:

for the update equations:

$$
\begin{gathered}
\mathrm{X}_{\mathrm{k}}=\phi_{\mathrm{k}, \mathrm{k}-1} \mathrm{X}_{\mathrm{k}-1}+\mathrm{W}_{\mathrm{k}, \mathrm{k}-1} \\
\mathrm{l}_{\mathrm{k}}=\mathrm{A}_{\mathrm{k}} \mathrm{X}_{\mathrm{k}}+\varepsilon_{\mathrm{k}}
\end{gathered}
$$

$$
\begin{gathered}
\widehat{\mathrm{X}}_{\mathrm{k}}(+)=\widehat{\mathrm{X}}_{\mathrm{k}}(-)+\mathrm{K}_{\mathrm{k}}\left\{\mathrm{l}_{\mathrm{k}}-\mathrm{A}_{\mathrm{k}} \widehat{\mathrm{X}}_{\mathrm{k}}(-)\right\} \\
\mathrm{C}_{\mathrm{k}}^{\mathrm{X}}(+)=\left\{\mathrm{I}-\mathrm{K}_{\mathrm{k}} \mathrm{A}_{\mathrm{k}}\right\} \mathrm{C}_{\mathrm{k}}^{\mathrm{X}}(-) \\
\mathrm{K}_{\mathrm{k}}=\mathrm{C}_{\mathrm{k}}^{\mathrm{X}}(-) \mathrm{A}_{\mathrm{k}}^{\mathrm{T}}\left\{\mathrm{A}_{\mathrm{k}} \mathrm{C}_{\mathrm{k}}^{\mathrm{X}}(-) \mathrm{A}_{\mathrm{k}}^{\mathrm{T}}+\mathrm{C}_{1}^{-1}\right\}^{-1}
\end{gathered}
$$

and for the prediction equations:

$$
\begin{gathered}
\widehat{\mathrm{X}}_{\mathrm{k}}(-)=\phi_{\mathrm{k}, \mathrm{k}-1} \widehat{\mathrm{X}}_{\mathrm{k}-1}(+) \\
\mathrm{C}_{\mathrm{k}}^{\mathrm{X}}(-)=\phi_{\mathrm{k}, \mathrm{k}-1} \mathrm{C}_{\mathrm{k}}^{\mathrm{X}}(+) \phi_{\mathrm{k}, \mathrm{k}-1}^{\mathrm{T}}+\mathrm{C}_{\mathrm{k}, \mathrm{k}-1}^{\mathrm{W}}
\end{gathered}
$$

where
$\mathrm{X}$ is the state vector,
$\Phi$ is the transition matrix,
I is the identity matrix,
$\mathrm{W}$ is the system process noise vector,
A is the design matrix,
$\varepsilon$ is the measurement noise,
$\mathrm{k}$ is the epoch number,
$\mathrm{CW}^{\mathrm{W}}$ is the covariance matrix of $\mathrm{W}$,
$\mathrm{K}$ is the Kalman gain matrix,
$\mathrm{C}_{\mathrm{l}} \quad$ is the covariance matrix of $\mathrm{l}$
$\mathrm{CX}^{\mathrm{X}}$ is the covariance matrix of $\mathrm{X}$
$(-)$ is a predicted quantity,
$(+)$ is and updated quantity,
$\left.{ }^{\wedge}\right)$ is an estimated quantity.

Different definitions of the transition matrix, $\Phi$, and the covariance of the system process noise, $\mathrm{Cw}$, can be used on the choice of the state space model for kinematic GPS [24]. The covariance matrix of the system process noise, $\mathrm{CW}^{\mathrm{w}}$, is given as:

$$
\mathrm{C}^{\mathrm{W}}=\int_{0}^{\Delta \mathrm{t}} \phi(\mathrm{z}) \mathrm{Q}(\mathrm{z}) \phi^{\mathrm{T}}(\mathrm{z}) \mathrm{dz}
$$

where $Q$ is the spectral density matrix. The state space model is affected by parameters such as, the system dynamics, state vector, and the assumption on the process behavior of the system [24,25]. The state space model plays an important role in improving the interpolation accuracy when the data rate is low. Okamura [26] have shown that with a 3 seconds data rate, positioning accuracy improves when using a constant velocity model and velocity accuracy improves when using a constant acceleration model. 
The Kalman filter can be implemented with different kinematic GPS models and different measurements. The process noise is also fully used in the filter by considering the spectral density matrix, $Q$, which allows the system to adjust the contribution to the estimates from the observables at the measurement epoch versus a contribution before the epoch.

The Kalman filter is usually employed in kinematic GPS applications where the remote receiver is installed on a moving platform and the reference receiver is set up on the ground station.

\subsubsection{Least Squares Algorithm}

The least squares algorithm for kinematic GPS does not use dynamic information [25]. In this algorithm, no assumption is made on the remote motion and no system process noise is considered. If a priori information about unknown parameter is used, the approach is called sequential least squares but if only observables at the measurement epoch are used, it is called the least squares approach.

If the measurement model is considered as:

$$
\mathrm{l}_{\mathrm{k}}=\mathrm{A}_{\mathrm{k}-1} \mathrm{X}_{\mathrm{k}-1}+\varepsilon_{\mathrm{k}-1}
$$

then the equation for the estimated vector and its covariance matrix in the sequential least squares approach are given as [18]:

$$
\begin{gathered}
\widehat{\mathrm{X}}_{\mathrm{k}}(-)=\widehat{\mathrm{X}}_{\mathrm{k}-1}(+)+\Delta \mathrm{X} \\
\mathrm{C}_{\mathrm{k}}^{\mathrm{X}}(-)=\mathrm{C}_{\mathrm{k}-1}^{\mathrm{X}}+\mathrm{C}^{\Delta \mathrm{X}} \\
\widehat{\mathrm{X}}_{\mathrm{k}}=\widehat{\mathrm{X}}_{\mathrm{k}}(-)+\left[\mathrm{A}_{\mathrm{k}}^{\mathrm{T}} \mathrm{C}_{1}^{-1} \mathrm{~A}_{\mathrm{k}}+\left\{\mathrm{C}_{\mathrm{k}}^{\mathrm{X}}\right\}^{-1}\right]^{-1} \mathrm{~A}_{\mathrm{k}}^{\mathrm{T}} \mathrm{C}_{1}^{-1}\left[\mathrm{l}_{\mathrm{k}}-\mathrm{A}_{\mathrm{k}} \widehat{\mathrm{X}}_{\mathrm{k}}(-)\right] \\
\mathrm{C}_{\mathrm{k}}^{\mathrm{X}}=\left[\mathrm{A}_{\mathrm{k}}^{\mathrm{T}} \mathrm{C}_{1}^{-1} \mathrm{~A}_{\mathrm{k}}+\left\{\mathrm{C}_{\mathrm{k}}^{\mathrm{X}}(-)\right\}^{-1}\right]^{-1}
\end{gathered}
$$

where

$\mathrm{C} \Delta \mathrm{X} \quad$ is the covariance matrix of $\Delta \mathrm{X}$,

$\Delta \mathrm{X} \quad$ is the increment vector over two successive epochs,

$(-) \quad$ is for an estimate based on data collected before epoch $\mathrm{k}$.

The equations for least squares approach are written as:

$$
\begin{gathered}
\widehat{\mathrm{X}}_{\mathrm{k}}=\left[\mathrm{A}_{\mathrm{k}}^{\mathrm{T}} \mathrm{C}_{1}^{-1} \mathrm{~A}_{\mathrm{k}}\right]^{-1} \mathrm{~A}_{\mathrm{k}}^{\mathrm{T}} \mathrm{C}_{1}^{-1} \mathrm{l}_{\mathrm{k}} \\
\mathrm{C}_{\mathrm{k}}^{\mathrm{X}}=\left[\mathrm{A}_{\mathrm{k}}^{\mathrm{T}} \mathrm{C}_{1}^{-1} \mathrm{~A}_{\mathrm{k}}\right]^{-1}
\end{gathered}
$$

In the least squares approach, the discrete position of the remote station is computed by using observations at one epoch, without any need of the process noise information or dynamic assumption. Therefore, the positioning solutions in successive epoch are independent. This approach can be applied to the case when reference is used either in static or in kinematic mode and a high data rate is used.

The advantages of using Kalman filter is that it has a general form of the equations which allows the implementation of different kinematic GPS models and measurements. In addition to this, because of its flexibility, it can meet the needs of a practical application in different dynamic environments.

\section{GPS and Strain Analysis}

The Global Positioning System (GPS) has revolutionized earth science in the last 25 years by providing geologists and geophysicists with real time monitoring of active deformation. Modern continuous geodetic GPS provides subcentimeter resolution of the displacement of monuments or stations relative to a stable reference frame. Because the changes in displacements measured are on the order of centimeters between stations separated by tens of kilometers, the deformation measured by GPS certainly qualifies as infinitesimal. 


\subsection{Dimensional Analysis}

Several first-order assumptions are made in this analysis:

- Plane-strain deformation in the horizontal plane.

- Neglecting the vertical velocities does not significantly affect the physical interpretation of our answer, recognizing that this might be a particularly poor assumption in areas characterized by significant uplift or subsidence.

- $\quad$ Strain is homogeneously distributed across the triangular area between the three GPS sites.

The input data are locations of GPS sites and their velocities, presented in units of length per time where "time" is usually one year. The input velocity data are (effectively) instantaneous velocities, so the output data should properly be expressed as rates. In the limit as time shrinks to zero, the velocity vector and the displacement vector converge and become identical as defined in the same reference frame. Hence, we retain the usual terminology of a displacement gradient tensor rather than a velocity gradient tensor in the discussion that follows.

The GPS data acquisition and analysis process resolves very small displacements. The mean velocities are computed from a time series comprised of many of these daily displacements. The 2-D analysis using data from GPS sites is a perfectly constrained problem, with just the right number of known quantities to solve for the unknown quantities exactly. All of the input data have uncertainties associated with them. As a first-look at infinitesimal crustal strain, the 3-site triangle-strain problem provides a good foundation to build on. The perfectly constrained triangle-strain problem by itself is not sufficient to provide a detailed characterization of tectonic strains in an area. A full understanding of present-day crustal strain in a given area requires information from all locally available GPS sites as well as other geological or geophysical data. Due consideration would have to be paid to how a variety of non-tectonic factors might affect the GPS velocity data, including flux of groundwater and surface water, igneous activity, deformation related to the earthquake cycle, mass movement that might affect a given GPS site, and so on.

After all the needed information from each of the GPS sites are acquired, the horizontal coordinates of the initial site location $\left(\mathrm{X}_{0}, \mathrm{Y}_{0}\right)$ as well as the east-west instantaneous velocity $\left(\mathrm{V}_{\mathrm{X}}\right)$ and the north-south instantaneous velocity $\left(\mathrm{V}_{\mathrm{Y}}\right)$ of each site will be known (Figure 4). The site location coordinates expressed in the Universal Transverse Mercator (UTM) system are in meter units, so the instantaneous velocities are expressed in meter/year units. Other unknown quantities have to compute: the coordinates of the translation velocity vector $\left(t_{X}, t_{Y}\right)$, the magnitude of the angular velocity vector $(\Omega)$ in nano-radian per year, and the elements of the strain rate tensor ( $\left.\varepsilon_{\mathrm{XX}}, \varepsilon_{\mathrm{XY}}, \varepsilon_{\mathrm{YX}}, \varepsilon_{\mathrm{YY}}\right)$. The units used in infinitesimal strain-rate studies using GPS data are nano-strains per year.

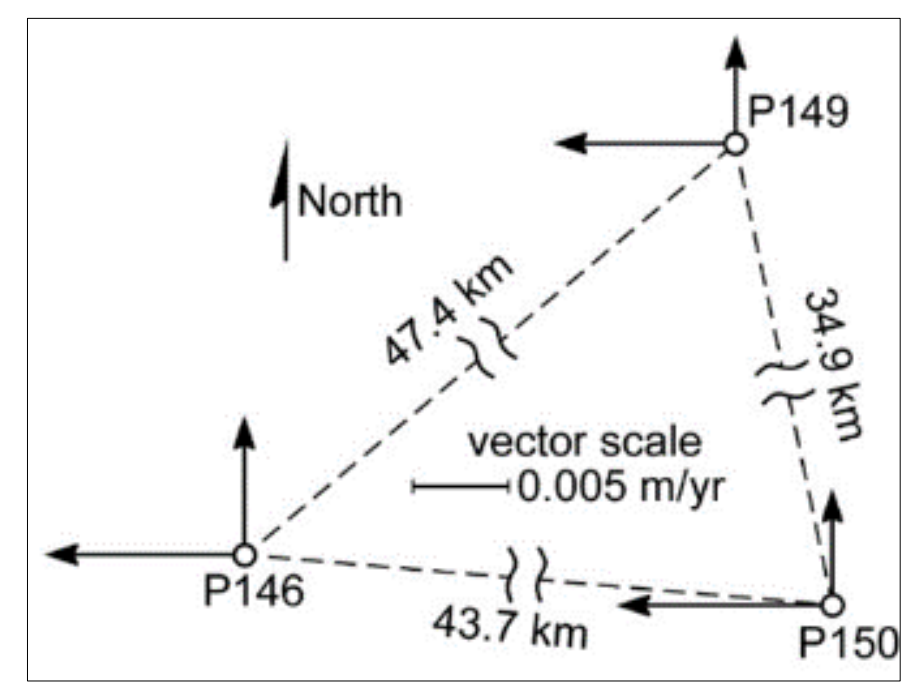

Figure 4 Illustration of three GPS sites separated from one another by tens of kilometers

The velocities measured at the three GPS sites are the result of three component velocities: translation, rotation and distortion of the crust.

deformation rate $=$ translation rate + rotation rate + distortion rate 
The translation velocity vector has the same magnitude and direction at all three sites as the triangle of stations simply move in space relative to the reference frame. The translation velocity vector as extending from the centroid of the triangle of initial GPS site locations to the centroid of the deformed triangle.

The rotational velocity vector (also known as an axial vector or angular velocity vector) in this 2 -D case is a vertical vector extending from the center of the triangle. A positive rotation is a counterclockwise rotation.

Imagine that you use the initial locations of our GPS sites, find the centroid of the triangle, and draw a (really) big circle around that center (Figure 5A). Then the GPS sites move, and the circle is distorted into an ellipse (Figure 5B and Figure 5D). You draw a blue line along the longer (major) axis of the ellipse, and a red line along the shorter (minor) axis that is $90^{\circ}$ from the trend of the major axis. You use your field compass to measure the trend of the major axis in the deformed state.

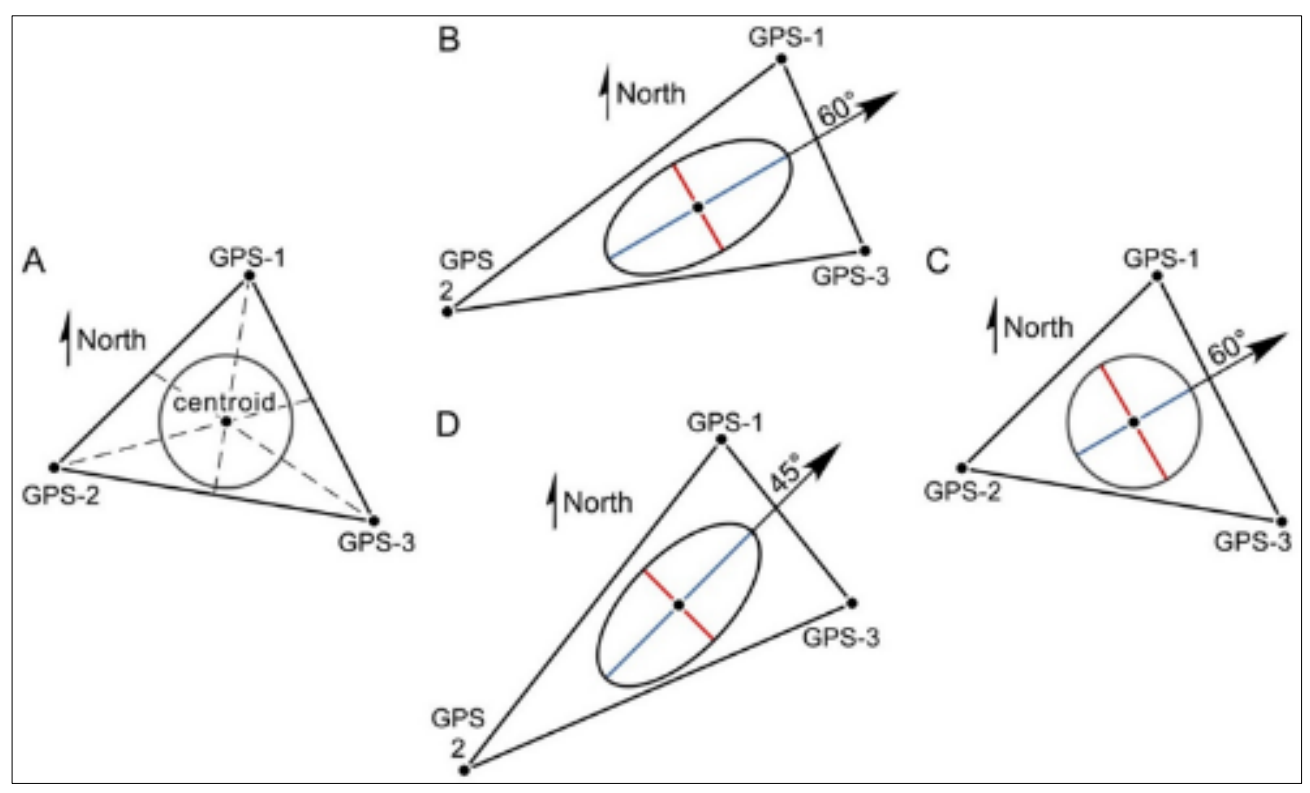

Figure 5 Defining rotation. A. Initial configuration of GPS triangle, with circle around the centroid of the triangle. B. Deformed triangle with circle changed to an ellipse. Major axis of the ellipse trends $60^{\circ}$ and is blue; minor axis is red. C. Retrodeformed triangle showing orientation of red and blue material lines prior to deformation. Trend of blue line is $60^{\circ}$, so deformation shown in B did not involve rotation. D. Second example of deformed triangle. Major axis trends $45^{\circ}$ and the same material line in the original triangle trended $60^{\circ}$, so this deformed triangle has undergone a positive (counterclockwise) rotation

The blue line in the circle has the same trend as it had as the major axis of the ellipse, in which case there was no bulk rotation of the triangle during deformation (Figure 5B). If the trend of the blue line changed during deformation, that change in angle is the bulk rotation (Figure 5D). Distortion includes a change in shape (strain) as well as any change in volume/area (dilation).

The 2-D displacement gradient tensor is an asymmetric matrix that can be decomposed into the sum of a symmetric tensor and an antisymmetric tensor, representing rates of both distortion and rotation. The rotational-velocity matrix is antisymmetric.

The infinitesimal strain-rate tensor $\varepsilon_{\mathrm{ij}}$ is symmetric,

$$
\Omega_{\mathrm{ij}}=\left[\begin{array}{cc}
0 & \Omega \\
\Omega & 0
\end{array}\right]
$$

$$
\varepsilon_{\mathrm{ij}}=\left[\begin{array}{ll}
\varepsilon_{\mathrm{xx}} & \varepsilon_{\mathrm{xy}} \\
\varepsilon_{\mathrm{yx}} & \varepsilon_{\mathrm{yy}}
\end{array}\right]
$$

so that $\varepsilon_{\mathrm{xy}}=\varepsilon_{\mathrm{yx}}$ and the 2-D strain-rate tensor thus contains only three independent variables: $\varepsilon_{\mathrm{XX}} \varepsilon_{\mathrm{XY}}=\varepsilon_{\mathrm{YX}}$ and $\varepsilon_{\mathrm{YY}}$. Adding these two tensors together would result in the displacement-rate gradient tensor $\mathrm{e}_{\mathrm{ij}}$ 


$$
\mathrm{e}_{\mathrm{ij}}=\left[\begin{array}{cc}
\varepsilon_{\mathrm{xx}} & \varepsilon_{\mathrm{xy}}-\Omega \\
\varepsilon_{\mathrm{yx}}+\Omega & \varepsilon_{\mathrm{yy}}
\end{array}\right]
$$

to which the translation terms $\left\{\mathrm{t}_{\mathrm{x}}, \mathrm{t}_{\mathrm{Y}}\right\}$ could be added, so that we account for all elements of the deformation

$$
\left[\begin{array}{cc}
\varepsilon_{\mathrm{xx}} & \varepsilon_{\mathrm{xy}}-\Omega \\
\varepsilon_{\mathrm{yx}}+\Omega & \varepsilon_{\mathrm{yy}}
\end{array}\right]+\left[\begin{array}{c}
\mathrm{t}_{\mathrm{x}} \\
\mathrm{t}_{\mathrm{y}}
\end{array}\right]
$$

Note that the translation is independent of position. The complete matrix equation for the deformation at an individual site, given its initial location $\left\{\mathrm{X}_{0}, \mathrm{Y}_{0}\right\}$ and the corresponding east velocity $\left(\mathrm{V}_{\mathrm{X}}\right)$ and north velocity $\left(\mathrm{V}_{\mathrm{Y}}\right)$ is

$$
\left[\begin{array}{c}
\mathrm{v}_{\mathrm{x}} \\
\mathrm{v}_{\mathrm{y}}
\end{array}\right]=\left[\begin{array}{cc}
\varepsilon_{\mathrm{xx}} & \varepsilon_{\mathrm{xy}}-\Omega \\
\varepsilon_{\mathrm{yx}}+\Omega & \varepsilon_{\mathrm{yy}}
\end{array}\right]\left[\begin{array}{l}
\mathrm{x}_{0} \\
\mathrm{y}_{0}
\end{array}\right]+\left[\begin{array}{l}
\mathrm{t}_{\mathrm{x}} \\
\mathrm{t}_{\mathrm{y}}
\end{array}\right]
$$

which can be unpacked to yield the following two equations with six unknowns: tx, ty, $\Omega, \varepsilon X x, \varepsilon X Y$ and $\varepsilon Y Y$

$$
\begin{aligned}
& \mathrm{v}_{\mathrm{x}}=\left(\mathrm{x}_{0} \varepsilon_{\mathrm{xx}}\right)+\left(\mathrm{y}_{0} \varepsilon_{\mathrm{xy}}\right)-\left(\mathrm{y}_{0} \Omega\right)+\left(\mathrm{t}_{\mathrm{x}}\right) \\
& \mathrm{v}_{\mathrm{y}}=\left(\mathrm{x}_{0} \varepsilon_{\mathrm{xx}}\right)+\left(\mathrm{x}_{0} \Omega\right)+\left(\mathrm{y}_{0} \varepsilon_{\mathrm{yy}}\right)+\left(\mathrm{t}_{\mathrm{y}}\right)
\end{aligned}
$$

GPS data give us the horizontal velocities ( $v_{x}$ and $v_{Y}$ ) for all three sites. Thus, there are six equations (2 for each site) with six unknowns, which makes this a perfectly constrained problem that will yield an exact answer.

The principal strain axes are found by computing the eigenvectors of the 2-D strain tensor $\varepsilon_{\mathrm{ij}}$. The eigenvectors are unit vectors in the directions of the principal strain axes. The eigenvalues of $\varepsilon_{i j}$ are the principal extensions in the principal directions. The larger of the two eigenvalues is the greater principal extension, $\mathrm{e}_{1}$, and the length of the semi-major axis of the horizontal strain ellipse is equal to the greater principal strain, $\mathrm{S}_{1}=\mathrm{e}_{1}+1$. The semi-minor axis is $\mathrm{S}_{2}=\mathrm{e}_{2}+1$, where $\mathrm{e}_{2}$ is the lesser principal extension.

In the specific case in which we have a 2-D strain tensor

$$
\varepsilon_{\mathrm{ij}}=\left[\begin{array}{ll}
\varepsilon_{11} & \varepsilon_{12} \\
\varepsilon_{21} & \varepsilon_{22}
\end{array}\right]
$$

the eigenvalues are given by

$$
\lambda=\frac{\left(\varepsilon_{11}+\varepsilon_{22}\right) \pm \sqrt{\left(4 \varepsilon_{12} \varepsilon_{21}\right)+\left(\varepsilon_{11}-\varepsilon_{22}\right)^{2}}}{2}
$$

The larger eigenvalue is $\lambda_{1}$ (also known as $\mathrm{e}_{1}$ ) and the smaller eigenvalue is $\lambda_{2}$ (also known as $\mathrm{e}_{2}$ ). An eigenvector corresponding to $\lambda_{1}$ is

$$
\left\{1, \frac{\lambda_{1}-\varepsilon_{11}}{\varepsilon_{12}}\right\}
$$

and an eigenvector associated with $\lambda_{2}$ is

$$
\left\{1, \frac{\lambda_{2}-\varepsilon_{11}}{\varepsilon_{12}}\right\}
$$

The unit eigenvectors can then be determined by dividing each of the components of these vectors by their length or norm. For example, the unit eigenvector associated with eigenvalue $\lambda_{1}$ is

$$
\left\{\frac{1}{\sqrt{1+\left(\frac{\left(\lambda_{1}-\varepsilon_{11}\right)}{\varepsilon_{12}}\right)^{2}}}, \frac{\frac{\left(\lambda_{1}-\varepsilon_{11}\right)}{\varepsilon_{12}}}{\sqrt{1+\left(\frac{\left(\lambda_{1}-\varepsilon_{11}\right)}{\varepsilon_{12}}\right)^{2}}}\right\}
$$

The magnitude of the infinitesimal shear strain $\left(\gamma_{\max }\right)$ at $45^{\circ}$ to the maximum principal strain axis can be computed a couple of different ways, given the data we now have in hand. 


$$
\begin{gathered}
\gamma_{\max }=2 \sqrt{\left(\frac{\varepsilon_{11}-\varepsilon_{22}}{2}\right)^{2}+\left(\varepsilon_{11}\right)^{2}} \\
\gamma_{\max }=\mathrm{e}_{1}-\mathrm{e}_{2}
\end{gathered}
$$

The area strain, which is also the first invariant of the 2-D strain tensor, is given by

$$
\text { area strain }=\varepsilon_{11}+\varepsilon_{22}=e_{1}+e_{2}=\left(S_{1} S_{2}\right)-1
$$

The second invariant of the 2-D strain tensor is

$$
\left(\varepsilon_{11} \varepsilon_{22}\right)-\varepsilon_{12}^{2}=\mathrm{e}_{1} \mathrm{e}_{2}
$$

and the third invariant is

$$
\operatorname{determinant}\left[\varepsilon_{\mathrm{ij}}\right]=\mathrm{e}_{1} \mathrm{e}_{2}
$$

\section{Results and Discussions}

\subsection{Research Workflow and Study Area}

The workflow of our study is depicted as shown in Figure 6. All rinex files are processed using GAMIT 10.7 to get geodetic, geocentric and topocentric coordinates. Velocity of displacement is calculated in mm/year and Delaunay triangle was applied for strain calculation.

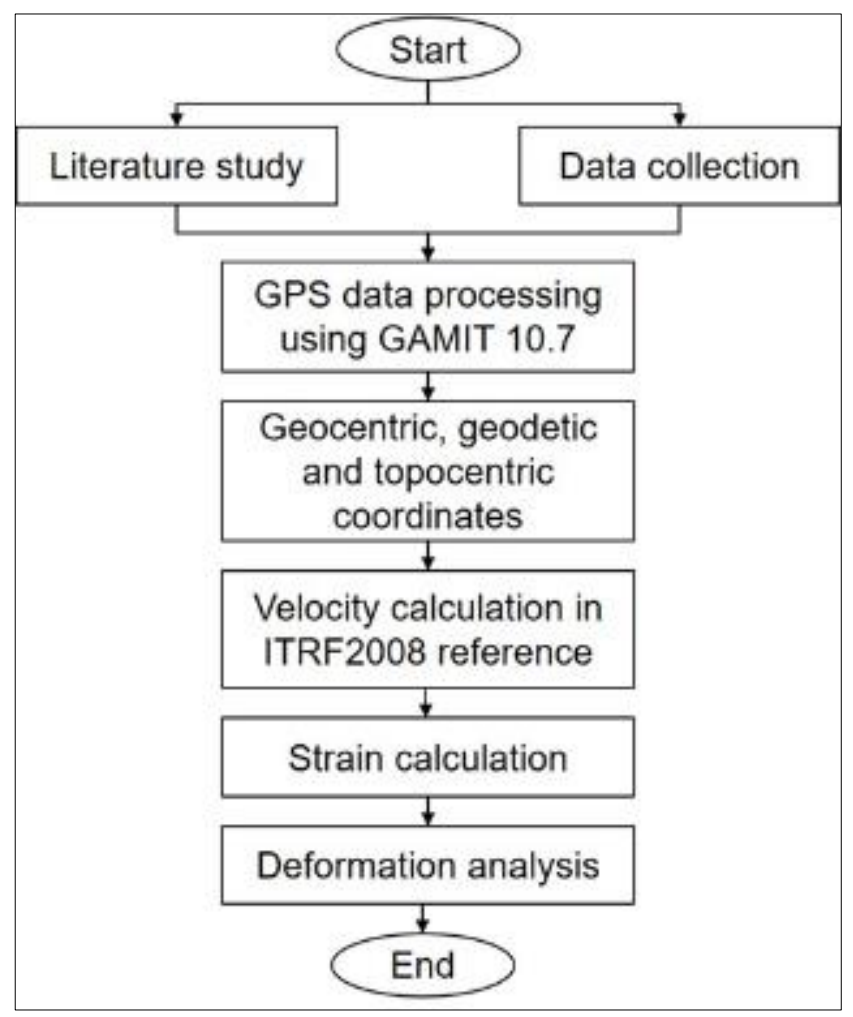

Figure 6 Research method flowchart

The study areas consist of southeast regions of Korean Peninsula to southwest regions of Japan (Figure 7) with continuous GPS stations used in this study are listed below. 


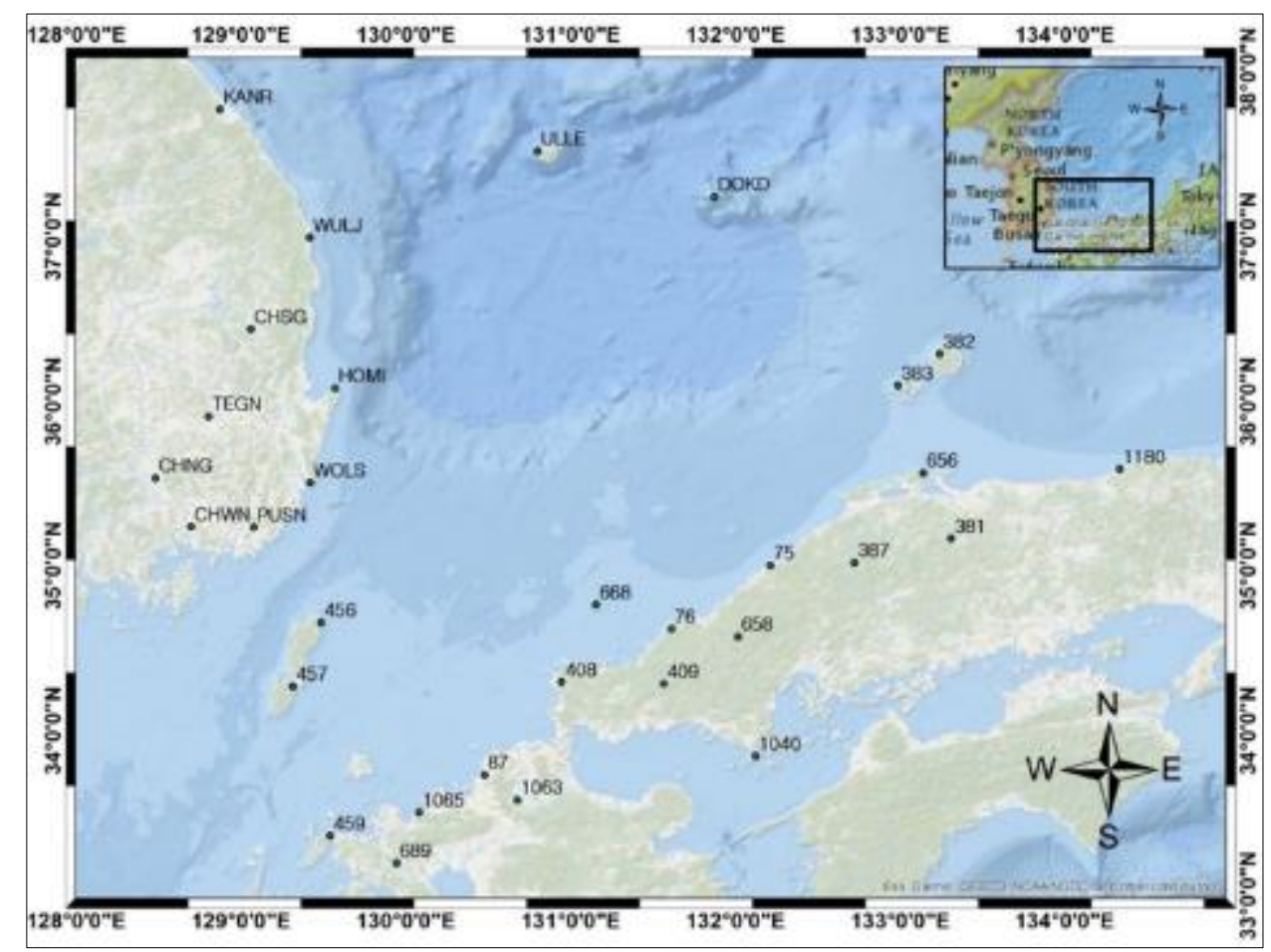

Figure 7 Research area

Table 2 List of continuous GPS stations

\begin{tabular}{|l|c|c|}
\hline Korea continuous GPS stations & \multicolumn{2}{|l|}{ Japan continuous GPS stations } \\
\hline Gangneung (KANR) & 0456 & 0076 \\
\hline Uljin (WULJ) & 0457 & 0087 \\
\hline Ulleung (ULLE) & 0459 & 0658 \\
\hline Dokdo (DOKD) & 0689 & 0075 \\
\hline Cheongsong (CHSG) & 1065 & 0387 \\
\hline Homi (HOMI) & 1063 & 0381 \\
\hline Daegu (TEGN) & 0408 & 0656 \\
\hline Ulsan (WOLS) & 0409 & 1180 \\
\hline Busan (PUSN) & 1040 & 0383 \\
\hline Changwon (CHWN) & 0668 & 0382 \\
\hline Changnyeong (CHNG) & & \\
\hline $\begin{array}{l}\text { International Global Navigation Satellite System } \\
\text { Service (IGS) stations }\end{array}$ & $\begin{array}{l}\text { BJFS, IRKT, KHAJ, SHAO, WUHN, YSSK, } \\
\text { SUWN, DAEJ, AIRA, BJNM, CCJ2. TCMS }\end{array}$ \\
\hline
\end{tabular}

\subsection{Time Series Analysis}

At the periodic points of time, collecting data through observation of a response variable is called a time series. Time series appear while saving sequential values of variable in clear time space. Free variable can change content of study topic in time series. It can appear as in geodesy science with changes of coordinate components. Time series analysis is an important part of geodetic and geodynamic studies, especially when continuous GPS observations are used to explore areas with a low rate of deformation. Velocity estimates obtained from GPS coordinate time series are used widely to identify and investigate possible geophysical phenomena in desired areas. Therefore, rate of the measured coordinates should be estimated accurately in order to be able to give an appropriate of the received GPS signals. 


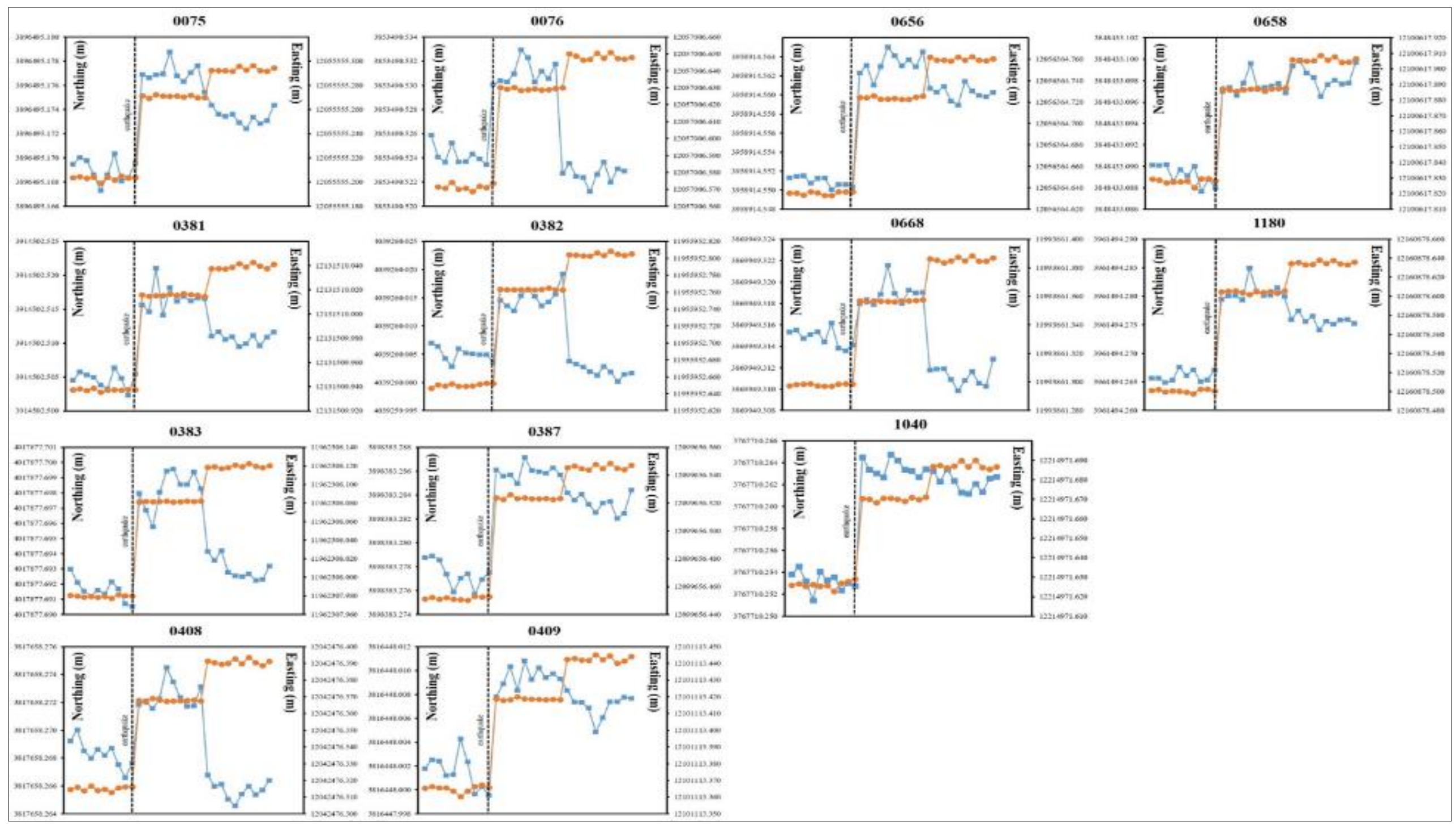

Figure 8 Japan's continuous GPS stations (1) 


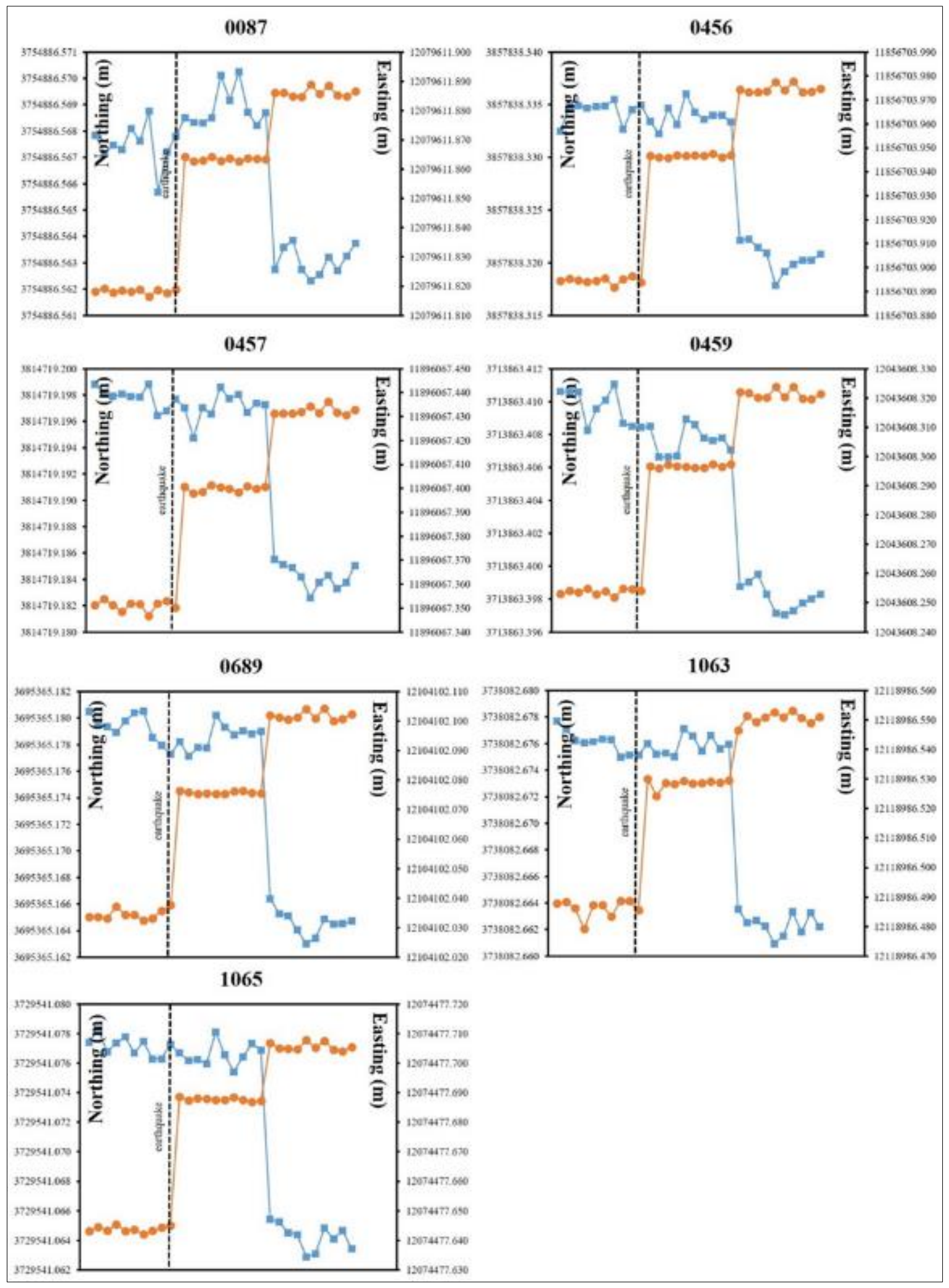

Figure 9 Japan's continuous GPS stations (2)

The result of GPS data processing using GAMIT 10.7 are geocentric to topocentric coordinates. The time series of all continuous GPS sites can be seen in Figure 8, Figure 9 and Figure 10. Position of each stations are indicated in Northing and Easting components. 


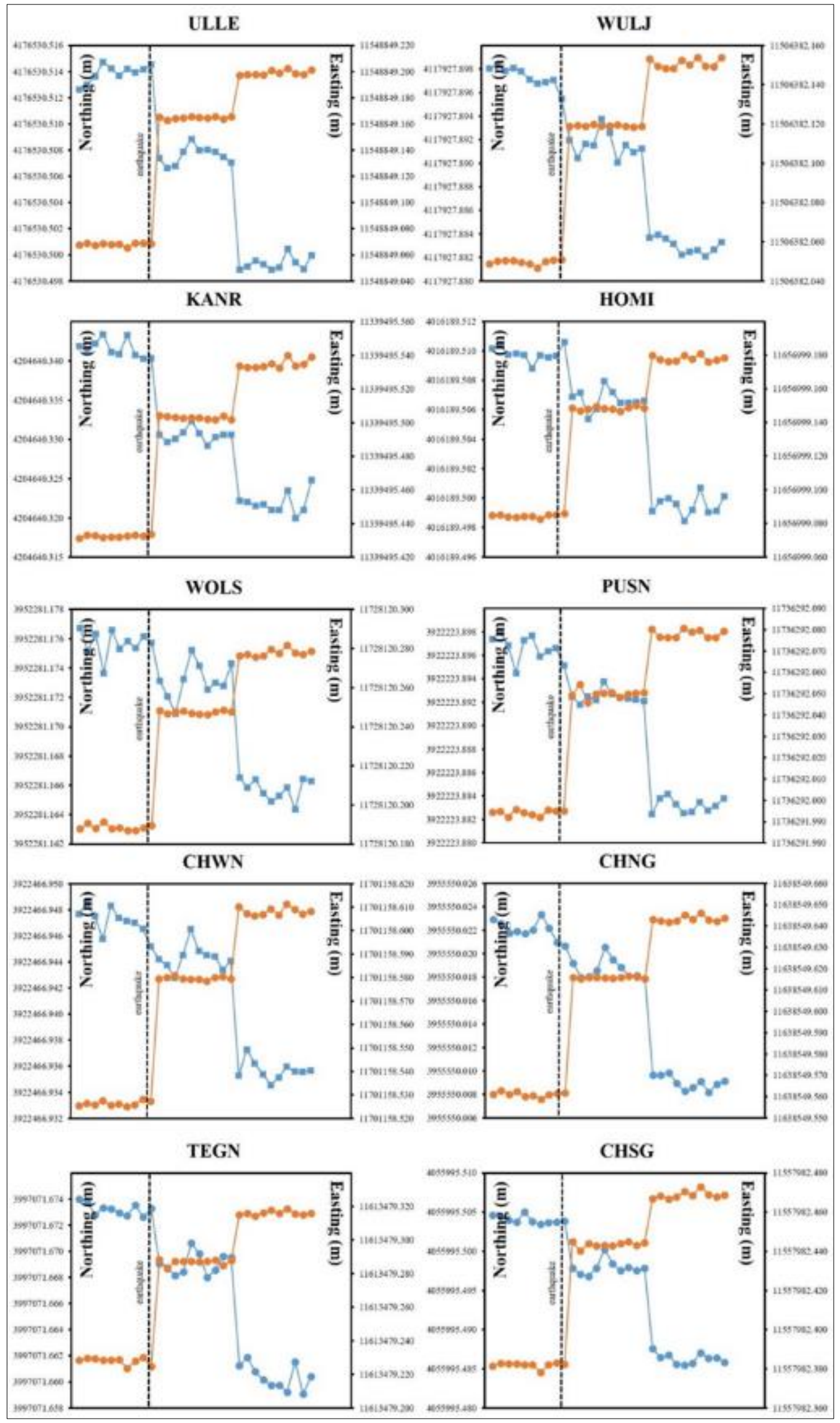

Figure 10 Korea's continuous GPS stations 
From the Figure 8 and Figure 9 above, all stations in Japan are continuously move eastward. On the other hand, all stations in Korea shown in Figure 10 show the same pattern of movement toward southeast direction. They do not show a significant difference between others compared with stations in Japan. The trend of movement of all Japan stations according to Northing axis shows some different patterns regarding to the occurrence of the earthquake. One reas on might be from the different fault characteristics between Chugoku and northern Kyushu. A study conducted by Okamura [26] has divided into three domains based on different fault characteristics observed in study area. The study found a NW-trending fault in northern Kyushu, while there are many NE-striking faults characterized in western Chugoku as shown in Figure 11.

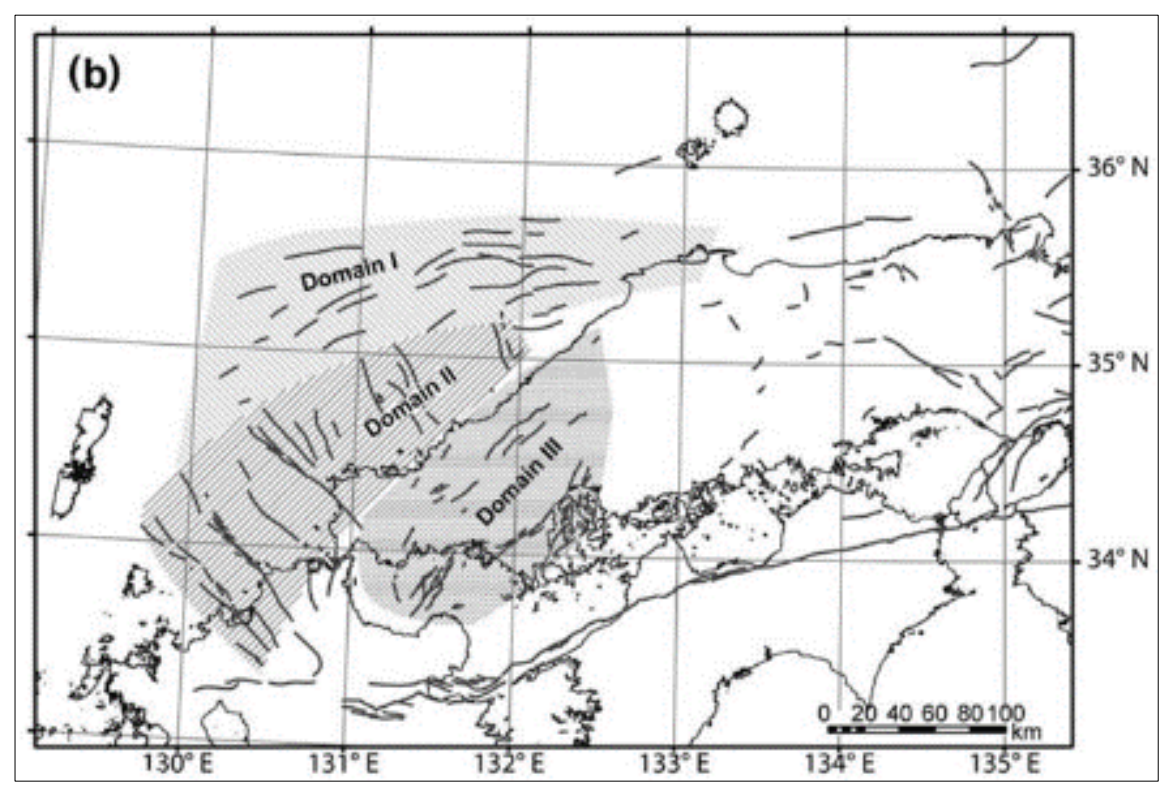

Figure 11 Fault domains I, II, and III defined on the basis of fault trend [26]

\subsection{Horizontal Velocity}

From the time series, velocity estimation results in this research area for each continuous GPS sites in ITRF2008 reference are shown in Figure 12.

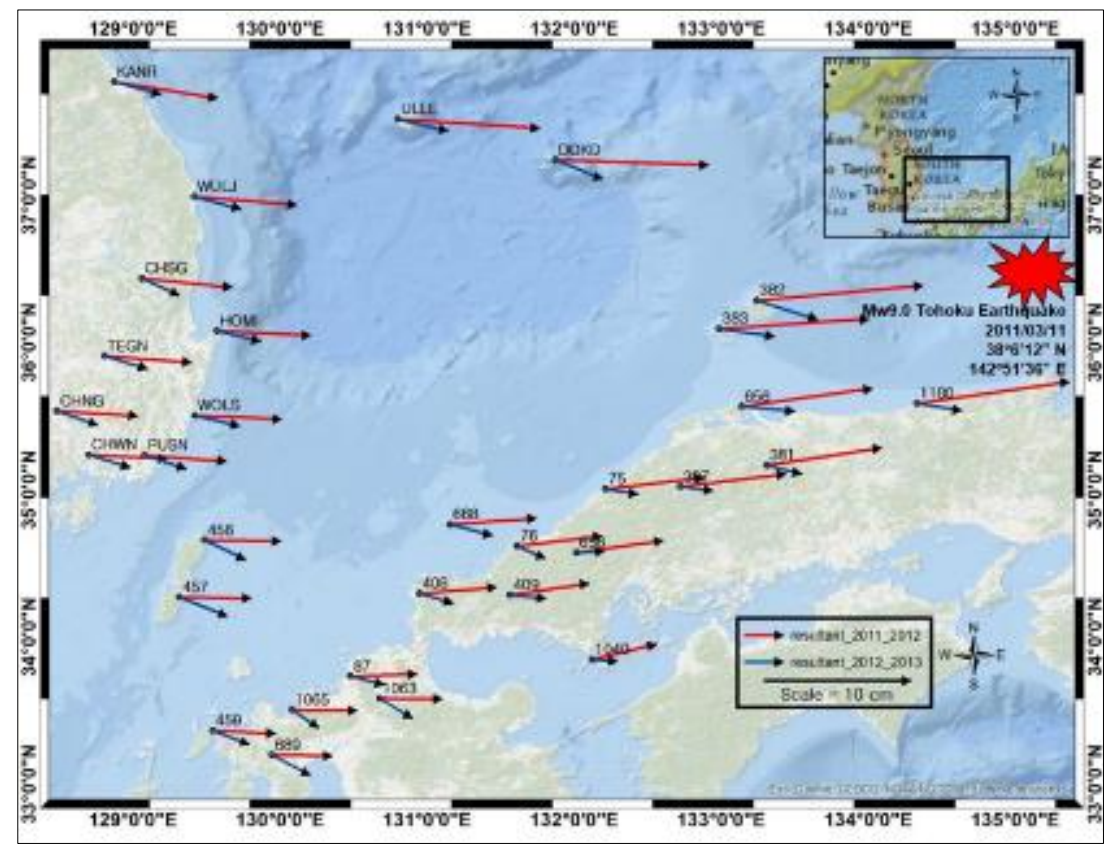

Figure 12 Velocity of continuous GPS sites in ITRF2008 reference 
The velocities are represented by red and blue arrows for year 2012 and 2013, respectively, with various trends of direction and for each site in ITRF2008 reference. From Figure 12 above it shows that the directions of the velocity among year 2011 to year 2012 in ITRF2008 reference move northeastward toward the epicenter of the earthquake with various magnitude. For example the stations which located closer to the epicenter show the bigger velocity indicated by the length of arrows. However, among year 2012 to year 2013 all stations move southeastward with lower velocity than before. In year 2013, the average magnitude of velocity in South Korea is observed about $31.332 \mathrm{~mm} / \mathrm{year}$. This finding is also found by Kim et al. [27] which stated the average magnitude decreased to $31 \mathrm{~mm} / \mathrm{year}$ after the mainshock of the Tohoku earthquake to 2013. Direction of movement from all stations indicate the direction of movement from Eurasian plate. Table 3 will show the velocity component for each continuous GPS sites in this research area.

Table 3 List of velocity component according to ITRF2008 reference frame

\begin{tabular}{|c|c|c|c|c|c|c|}
\hline $\begin{array}{l}\text { Station } \\
\text { Name }\end{array}$ & $\begin{array}{l}\text { Longitude } \\
\left({ }^{\circ}\right)\end{array}$ & $\begin{array}{l}\text { Latitude } \\
\left({ }^{\circ}\right)\end{array}$ & $\begin{array}{l}2012 \text { Easting } \\
\text { Velocity } \\
\text { (mm/year) }\end{array}$ & $\begin{array}{l}2012 \text { Northing } \\
\text { Velocity } \\
\text { (mm/year) }\end{array}$ & $\begin{array}{l}2013 \text { Easting } \\
\text { Velocity } \\
\text { (mm/year) }\end{array}$ & $\begin{array}{l}2013 \text { Northing } \\
\text { Velocity } \\
\text { (mm/year) }\end{array}$ \\
\hline ULLE & 130.798 & 37.518 & 96.572 & -6.285 & 34.322 & -8.242 \\
\hline DOKD & 131.870 & 37.239 & 104.080 & -3.429 & 32.100 & -13.017 \\
\hline KANR & 128.868 & 37.771 & 70.355 & -11.051 & 31.891 & -8.614 \\
\hline WULJ & 129.413 & 36.992 & 69.458 & -5.774 & 31.770 & -8.599 \\
\hline HOMI & 129.567 & 36.078 & 63.856 & -3.150 & 29.710 & -7.159 \\
\hline WOLS & 129.416 & 35.504 & 58.832 & -2.550 & 30.319 & -7.395 \\
\hline PUSN & 129.075 & 35.234 & 55.612 & -4.113 & 28.247 & -9.235 \\
\hline CHWN & 128.693 & 35.236 & 53.412 & -2.804 & 28.495 & -8.639 \\
\hline CHNG & 128.478 & 35.533 & 54.673 & -3.335 & 27.512 & -9.651 \\
\hline TEGN & 128.802 & 35.906 & 58.877 & -4.174 & 29.243 & -8.677 \\
\hline CHSG & 129.056 & 36.436 & 61.480 & -6.115 & 25.322 & -11.586 \\
\hline 1065 & 130.079 & 33.503 & 43.948 & -0.582 & 17.891 & -12.326 \\
\hline 0075 & 132.209 & 35.003 & 67.541 & 7.909 & 22.310 & -3.528 \\
\hline 0076 & 131.610 & 34.616 & 57.998 & 6.856 & 18.923 & -8.406 \\
\hline 0087 & 130.477 & 33.731 & 45.142 & 1.388 & 22.783 & -5.812 \\
\hline 0689 & 129.940 & 33.196 & 41.218 & -0.690 & 25.973 & -14.015 \\
\hline 0381 & 133.309 & 35.165 & 78.281 & 11.977 & 23.660 & -5.940 \\
\hline 0382 & 133.240 & 36.285 & 113.066 & 10.053 & 41.402 & -12.975 \\
\hline 0383 & 132.984 & 36.093 & 102.120 & 6.659 & 37.745 & -5.230 \\
\hline 0387 & 132.721 & 35.020 & 71.774 & 8.528 & 22.357 & -2.603 \\
\hline 1040 & 132.120 & 33.846 & 43.907 & 10.319 & 17.138 & -1.283 \\
\hline 0408 & 130.943 & 34.295 & 52.725 & 4.160 & 23.015 & -6.728 \\
\hline 0409 & 131.563 & 34.284 & 53.681 & 7.874 & 24.050 & -2.299 \\
\hline 0456 & 129.482 & 34.656 & 52.053 & -0.564 & 27.890 & -13.387 \\
\hline 0457 & 129.312 & 34.268 & 48.844 & -0.739 & 32.438 & -12.866 \\
\hline 1063 & 130.676 & 33.580 & 42.232 & -0.232 & 22.062 & -13.469 \\
\hline 0459 & 129.537 & 33.362 & 42.880 & -2.009 & 24.570 & -9.511 \\
\hline 0656 & 133.138 & 35.564 & 88.963 & 12.381 & 36.175 & -3.079 \\
\hline 0658 & 132.014 & 34.571 & 59.124 & 8.282 & 18.924 & 0.870 \\
\hline 0668 & 131.152 & 34.764 & 58.775 & 4.070 & 28.961 & -7.642 \\
\hline 1180 & 134.330 & 35.587 & 103.902 & 14.673 & 30.494 & -4.923 \\
\hline
\end{tabular}




\subsection{Strain}

Velocities of continuous GPS sites in ITRF2008 reference frame are used to calculate the principal strain with infinitesimal method. The Delaunay triangle is used to connect between GPS sites. From 31 continuous GPS sites in Korea and Japan that are used in this research, there are 47 triangles that connect each site. Figure 13 and Figure 14 are shown the distribution of strain right after the occurrence of Tohoku earthquake and 1-year interval after the Tohoku earthquake, respectively. In Figure 13, the direction of the principal axis of the maximum compression is ENE-WSW as a whole as the impact of the great Tohoku earthquake. The biggest strain occur in triangle D0KD-382-383 with magnitude $0.358 \mu$ strain/year, while the smallest strain occur in triangle 0087-0456-0457 with magnitude 0.047 $\mu$ strain/year. This might be occur because of the closeness to the epicenter of the earthquake. Table 4 will show the strain for each triangle in this research area.

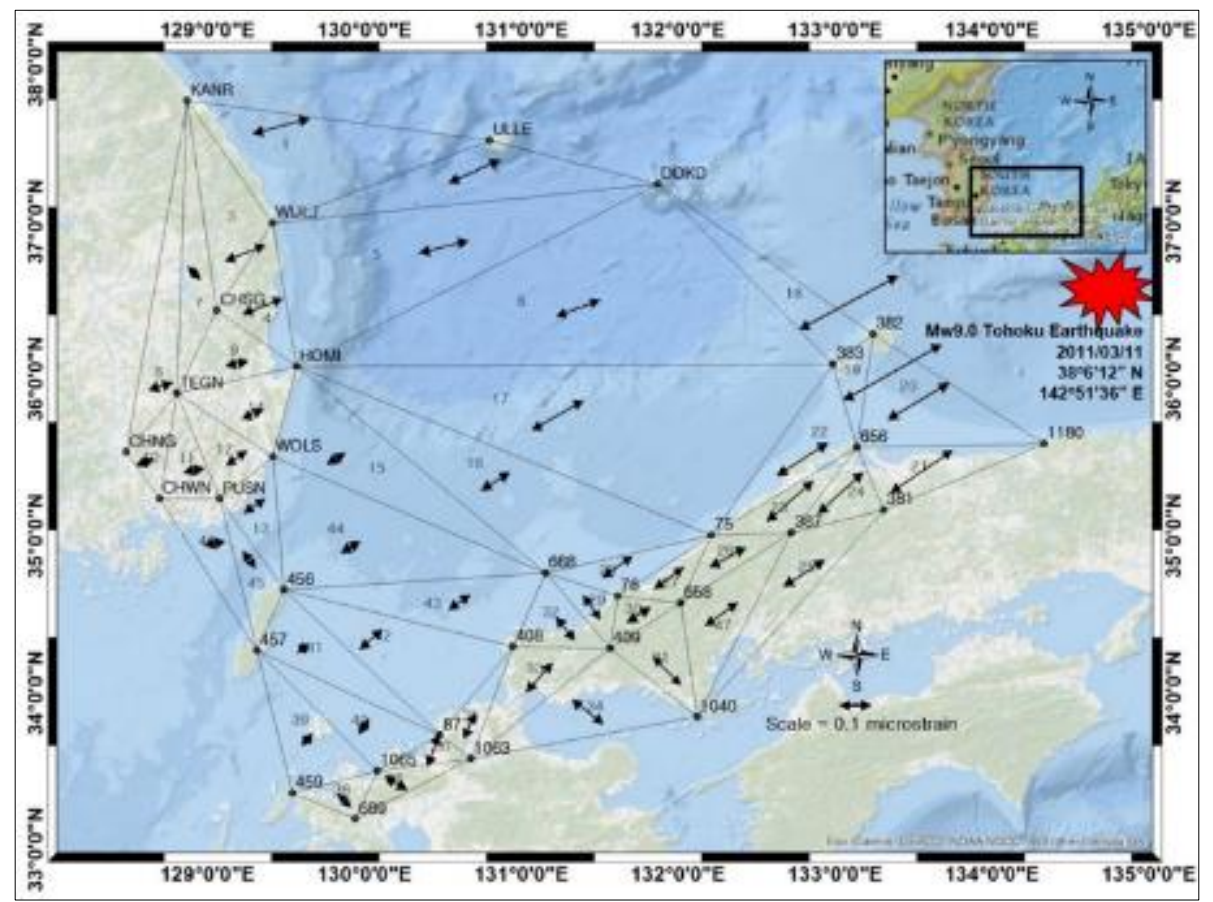

Figure 13 Distribution of strain on the occurrence of Tohoku earthquake

Table 4 Strain for each triangle in this research area

\begin{tabular}{|c|c|c|c|c|c|}
\hline $\begin{array}{l}\text { Triangle/ } \\
\text { Baseline }\end{array}$ & $\begin{array}{ll}\text { Year } & 2012 \\
\text { strain } & \\
\text { ( } \mu \text { strain) } & \end{array}$ & 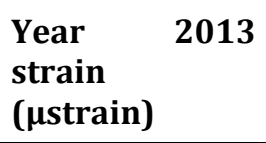 & $\begin{array}{l}\text { Triangle/ } \\
\text { Baseline }\end{array}$ & 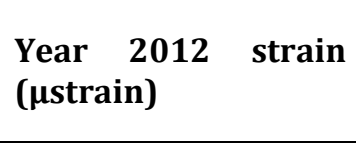 & 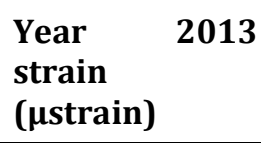 \\
\hline 1 & 0.187 & 0.018 & 25 & 0.154 & 0.035 \\
\hline 2 & 0.178 & 0.069 & 26 & 0.130 & -0.119 \\
\hline 3 & 0.138 & 0.122 & 27 & 0.116 & -0.255 \\
\hline 4 & 0.136 & 0.157 & 28 & 0.117 & -0.205 \\
\hline 5 & 0.159 & -0.017 & 29 & -0.093 & -0.330 \\
\hline 6 & 0.149 & -0.057 & 30 & 0.088 & -0.198 \\
\hline 7 & -0.061 & -0.236 & 31 & -0.127 & -0.133 \\
\hline 8 & 0.079 & 0.052 & 32 & -0.093 & -0.111 \\
\hline 9 & 0.072 & -0.069 & 33 & 0.123 & 0.087 \\
\hline 10 & 0.062 & 0.062 & 34 & -0.127 & 0.103 \\
\hline 11 & 0.066 & -0.008 & 35 & 0.089 & 0.225 \\
\hline
\end{tabular}




\begin{tabular}{|c|c|c|c|c|c|}
\hline 12 & 0.081 & 0.065 & 36 & 0.108 & 0.372 \\
\hline 13 & 0.082 & 0.069 & 37 & -0.080 & 0.251 \\
\hline 14 & 0.075 & 0.012 & 38 & -0.063 & 0.171 \\
\hline 15 & 0.068 & -0.013 & 39 & 0.052 & -0.148 \\
\hline 16 & 0.105 & -0.055 & 40 & 0.058 & 0.202 \\
\hline 17 & 0.190 & 0.066 & 41 & 0.047 & -0.123 \\
\hline 18 & 0.358 & -0.202 & 42 & 0.095 & -0.066 \\
\hline 19 & 0.357 & 0.152 & 43 & 0.082 & -0.096 \\
\hline 20 & 0.226 & -0.132 & 44 & 0.069 & 0.077 \\
\hline 21 & 0.240 & -0.134 & 45 & -0.067 & -0.149 \\
\hline 22 & 0.192 & 0.134 & 46 & 0.067 & 0.046 \\
\hline 23 & 0.195 & -0.139 & 47 & 0.127 & 0.049 \\
\hline 24 & 0.195 & -0.110 & & & \\
\hline
\end{tabular}

Figure 14 shows the distribution of strain in this research area after 1-year interval. The direction of the principal axis of the maximum compression in Korea is stay ENE-WSW as a whole, while the direction is changed to WNW-ESE for Japan. These results are also correspond with [16,28,29]. According to research conducted by Choi et al. [16], triangulation method was used for the whole Korea as the GPS data were not available in time. Their result is shown in Figure 15B. The result by Jun [28] is shown in Figure 15A. Though number of data was not so large, it is clear that the $\mathrm{P}$-axes in and around the peninsula are in the direction of ENE-WSW. Figure 15C shows the distribution of P-axis of western part of Honshu, Japan [29]. The direction of P-axis in the region of Japan Sea coast is WNW-ESE, as same as shown in Figure 14. There is a marked difference in the direction of the stress axis between Korean Peninsula and Japan. This suggests the likelihood of the existence of a certain tectonic line between the southern part of Korean peninsula and Japan.

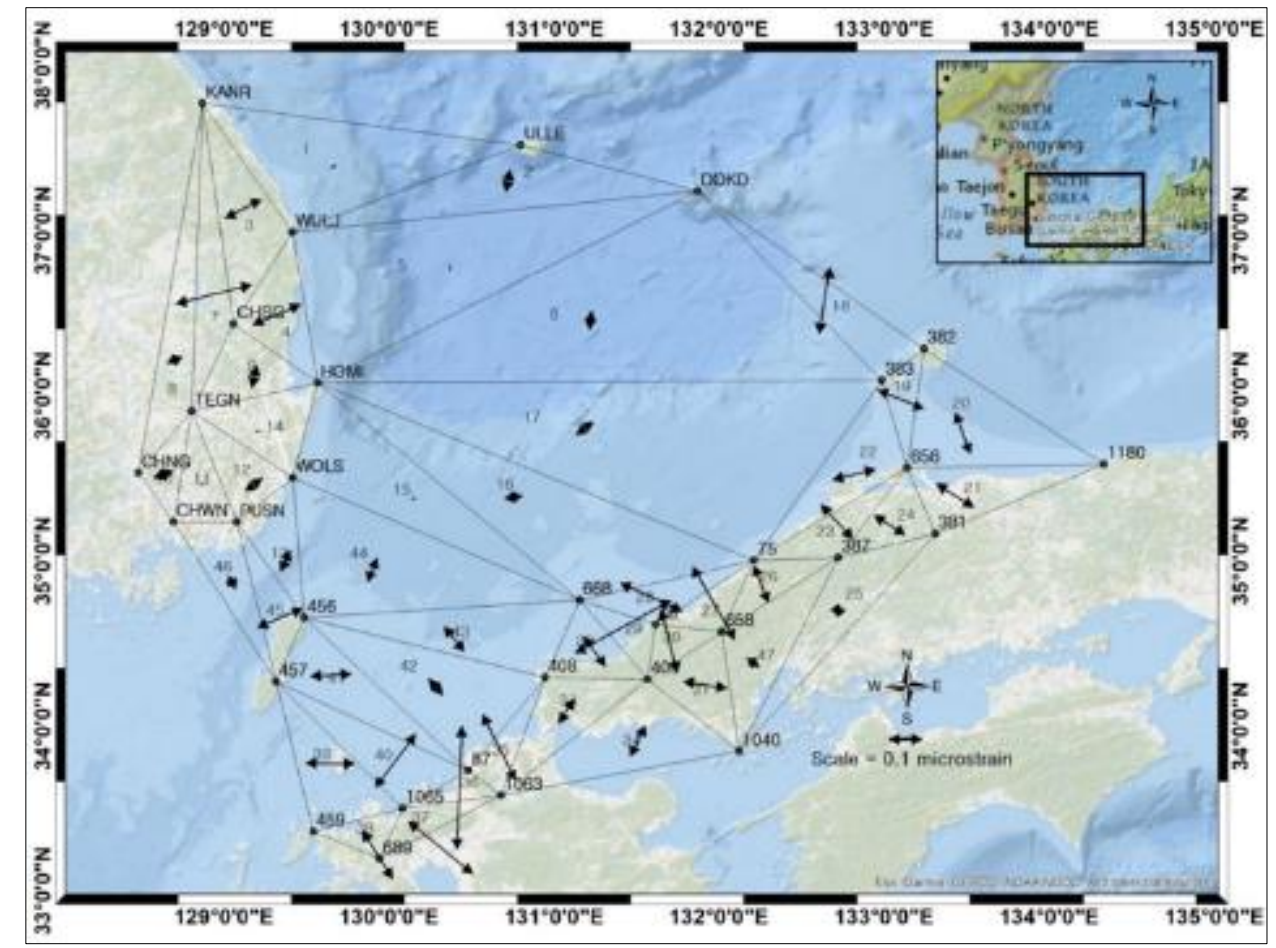

Figure 14 Distribution of strain after 1-year interval 


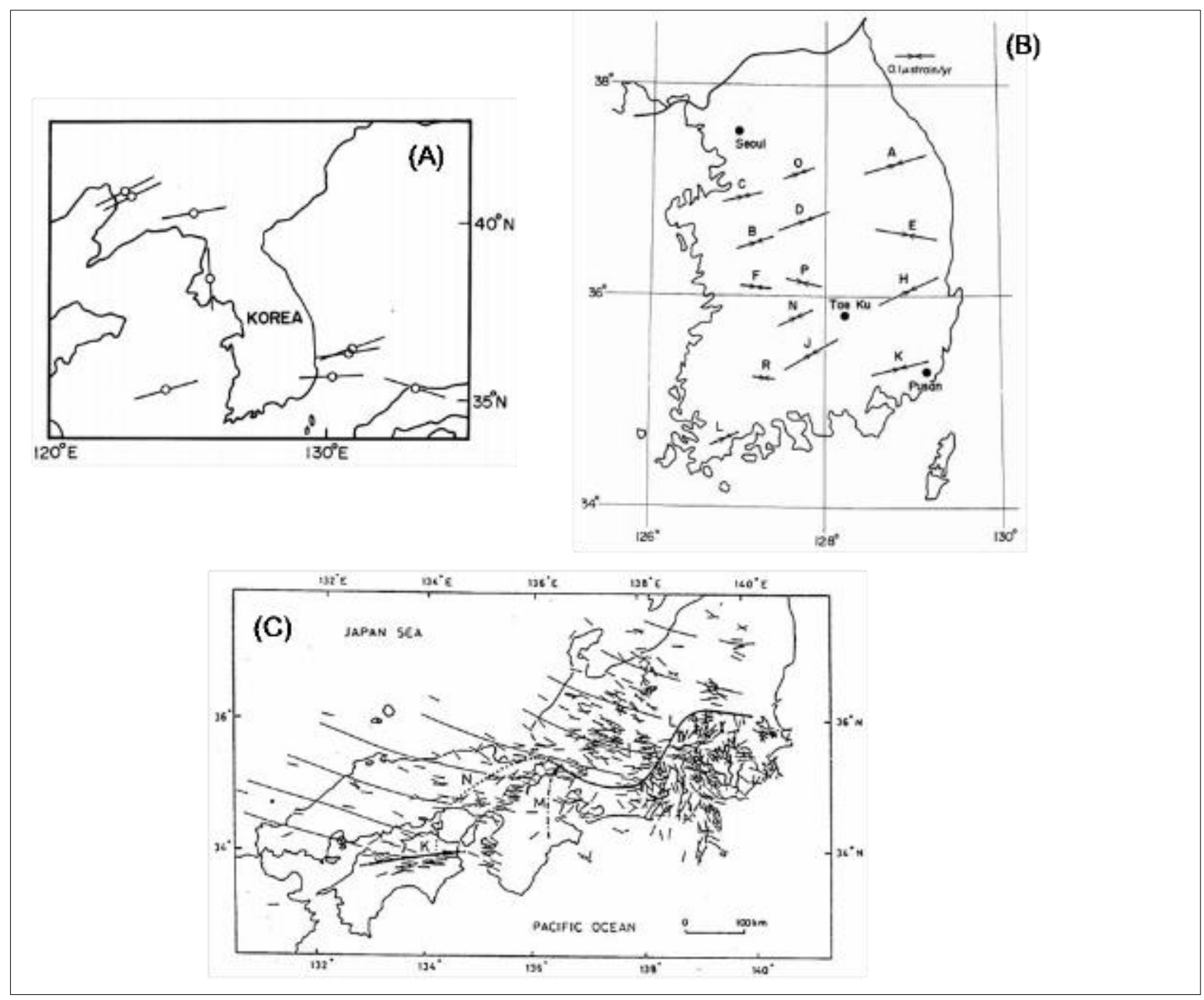

Figure 15 (A) Horizontal projection of P-axis of focal mechanism of the earthquakes in and around Korean Peninsula [28]; (B) Distribution of earth strain in Korea [16] and (C) Direction of the maximum compressional stress of the Western part of Honshi, Japan, deduced from P-axis of earthquake [29]

\section{Conclusion}

As the result of this research around the Korea Strait, the characters of deformation derived from GPS observation can be summarized as follows:

- This study indicates the closeness between station and epicenter plays an important role in affecting the displacement of each stations. Based on the GPS data observation from 2011 to 2012, tectonic in research area as the result of Mw9.0 Tohoku earthquake has maximum displacement rate of $113.512 \mathrm{~mm} /$ year $(\sim 11.3$ $\mathrm{cm} /$ year) in station 0382 in Japan relative to Eurasia plate.

- The strain results in research area from three years data with 31 continuous GPS sites show different pattern between the time of co-seismic and 1-year interval after the occurrence of earthquake. Between the year 2011 and 2012, when there is the occurrence of Tohoku earthquake, all the direction of the principal axis of the maximum compression is ENE-WSW at the range of -0.127 to $0.358 \mu$ strain, while the direction is mostly change to WNW-ESE in Japan a year after the occurrence of earthquake.

- The opposite direction of principal axis suggests the likelihood of the existence of a certain tectonic line between the southern part of Korean peninsula and Japan. 


\section{Compliance with ethical standards}

\section{Acknowledgments}

This research was supported by National Geographic Information Institute (NGII) of South Korea.

\section{Disclosure of conflict of interest}

No conflict of interest.

\section{References}

[1] Ishibe T, Shimazaki K, Satake K, Tsuruoka H. Change in seismicity beneath the Tokyo metropolitan area due to the 2011 off the Pacific coast of Tohoku Earthquake. Earth, Planets and Space. 2011; 63(7): 731-735.

[2] Nishimura T, Munekane H, Yarai H. The 2011 off the Pacific coast of Tohoku Earthquake and its aftershocks observed by GEONET. Earth, Planets and Space. 2011; 63(7): 631-363.

[3] Yagi Y, Fukahata Y. Rupture process of the 2011 Tohoku-oki earthquake and absolute elastic strain release. Geophysical Research Letters. 2011; 38(19).

[4] Suzuki W, Aoi S, Sekiguchi H, Kunugi T. Rupture process of the 2011 Tohoku-Oki mega-thrust earthquake (M9.0) inverted from strong-motion data. Geophysical Research Letters. 2011; 38(7).

[5] Fujii Y, Satake K, Sakai S, Shinohara M, Kanazawa T. Tsunami source of the 2011 off the Pacific coast of Tohoku Earthquake. Earth, Planets and Space. 2011; 63(7): 815-820.

[6] Hong T, Lee J, Houng S. Long-term evolution of intraplate seismicity in stress shadows after a megathrust. Physics of the Earth and Planetary Interiors. 2015; 245: 59-70.

[7] Pollitz F, Bürgmann R, Banerjee P. Geodetic slip model of the 2011 M9.0 Tohoku earthquake. Geophysical Research Letters. 2011; 38(7).

[8] Shestakov N, Takahashi H, Ohzono M, Prytkov A, Bykov V, Gerasimenko M, Luneva M, Gerasimov G, Kolomiets A, Bormotov V, Vasilenko N, Baek J, Park P, Serov M. Analysis of the far-field crustal displacements caused by the 2011 Great Tohoku earthquake inferred from continuous GPS observations. Tectonophysics. 2012; 524-525: 7686.

[9] Wang M, Li Q, Wang F, Zhang R, Wang Y, Shi H, Zhang P, Shen Z. Far-field coseismic displacements associated with the 2011 Tohoku-oki earthquake in Japan observed by Global Positioning System. Chinese Science Bulletin. 2011; 56(23): 2419-2424.

[10] Baek J, Shin Y, Na S, Shestakov N, Park P, Cho S. Coseismic and postseismic crustal deformations of the Korean Peninsula caused by the 2011 Mw 9.0 Tohoku earthquake, Japan, from global positioning system data. Terra Nova. 2012; 24(4): 295-300.

[11] Kim D, Park K, Ha J, Sohn D, Won J. Geodetic analysis of post-seismic crustal deformations occurring in South Korea due to the Tohoku-Oki earthquake. KSCE Journal of Civil Engineering. 2016; 20(7): 2885-2892.

[12] Choi H, Hong T, He X, Baag C. Seismic evidence for reverse activation of a paleo-rifting system in the East Sea (Sea of Japan). Tectonophysics. 2012; 572-573: 123-133.

[13] Park J, Kim W, Chung T, Baag C, Ree J. Focal mechanisms of recent earthquakes in the Southern Korean Peninsula. Geophysical Journal International. 2007; 169(3): 1103-1114.

[14] Miliken RJ, Zoller CJ. Principle of operation of NAVSTAR GPS and System Characteristics, Global Positioning System, Volume I, Institute of Navigation, Washington D.C. 1990; 3-14.

[15] Wells DE, N Beck, D, Delikaraoglou A, Kleusberg, EJ Krakiwsky, G Lachapelle, RB Langley, M Nakiboglou, KP Schwarz, JM Tranquilla, P Vanicek. Guide to GPS Positioning, Canadian GPS Associates, Fredericton. 1986.

[16] Choi JH, Sato H. Horizontal Strain of the Crust in Korea inferred from Geodetic Data. Journal of the Geodetic Society of Japan. 1987; 43(3): 159-180.

[17] Lachapelle G. GPS Observables and Error Sources for Kinematic Positioning, Proceedings of IAG international symposium 107 on kinematic systems in Geodesy, Surveying, and Remote Sensing, Springer Verlag, New York. $1991 ; 17-26$. 
[18] Erickson C. Investigations of C/A Code and Carrier Measurements and Techniques for Rapid Static GPS Surveys, M.Sc. Thesis, UCGE Report No. 20044, Department of Geomatics Engineering, University of Calgary. 1992.

[19] Liu C. (1993), Precise GPS Positioning in The Marine Environment, M.Sc. Thesis, UCGE Report No. 20055, Department of Geomatics Engineering, University of Calgary.

[20] Cannon ME. Kinematic Positioning Using GPS Pseudorange and Carrier Phase Observations, M. Sc. Thesis, Department of Geomatics Engineering, University of Calgary, Calgary. 1987.

[21] Cannon ME. Airborne GPS/INS with an Application to Aerotriangulation, Ph.D. Dissertation, Department of Geomatics Engineering, University of Calgary, Calgary. 1991.

[22] Remondi B. Using the Global Positioning System (GPS) Phase Observable for Relative Geodesy: Modeling, Processing, and Results, CSR-84-3, Centre for Space Research, The University of Texas, Austin. 1984.

[23] Georgiadou Y, Kleusberg A. Algorithms and results of kinematic GPS positioning. CISM journal. 1991; 45(4): 569575.

[24] Schwarz KP, Cannon ME, RVC Wong. A Comparison of GPS Kinematic Models for the Determination of Positions and Velocity along a Trajectory, Manuscripta Geodetica, Springer Verlag. 1989; 14: 345-353.

[25] Gelb A. Applied Optimal Estimation, The MIT Press, Cambridge, Mass, U.S.A. 1974.

[26] Okamura Y. Active tectonics around the junction of Southwest Japan and Ryukyu arcs: Control by subducting plate geometry and pre-Quaternary geologic structure. Island Arc. 2016; 25(4): 287-297.

[27] Kim S, Ree J, Yoon H, Choi B, Park P. Crustal Deformation of South Korea After the Tohoku-Oki Earthquake: Deformation Heterogeneity and Seismic Activity. Tectonics. 2018; 37(8): 2389-2403.

[28] Jun MS. Tectonic Implication of shallow Earthquakes in and around the Korean Peninsula, Journal of Uppsala University, Sweden. 1990; 285: 1-30.

[29] Tsukahara H, Y Kobayashi. Crustal Stress in the Central and Western part of Japan, Zisin. 1991; 2: 44, 221 -231.

[30] Black HD. An Easily Implemented Algorithm for Tropospheric Range Correction, Journal of Geophysical Research. 1978; 38(B4):1825-1828.

[31] Hopefield HS. Two-quadratic Tropospheric Refractivity Profile for Correcting Satellite Data, Journal of Geophysical Research. 1969; 74(I8): 4487-4499.

[32] Klobuchar J. Ionospheric Effect on Earth-Space Propagation, Report No. ERP- 866, Airforce Geophysics Laboratory, Hanscom, AFB, Mass. 1983.

[33] Krakiwsky EJ. The Method of Least Squares: A Synthesis of Advances, UCGE Report No. 10003, Department of Geomatics Engineering, University of Calgary. 1990.

[34] Martin EH. GPS User Equipment Error Models, Global Positioning System, Vol. 1, Institute of Navigation, Washington D.C. 1980; 109-118.

[35] Saastamoinen J. Contributions to the Theory of atmospheric Refraction, Bulletin Geodesique. 1973; 105-107, 279298, 283-297, 13-34.

[36] Shuanggen J, Wenyao Z. Active Motion of Tectonic Blocks in East Asia: Evidence from GPS Measurement. Acta Geologica Sinica - English Edition. 2010; 77(1): 59-63. 